\title{
On the Anomalous Behaviour of Scalar Flux-Variance Similarity Functions Within the Canopy Sub-layer of a Dense Alpine Forest
}

\author{
D. Cava - G. G. Katul • A. M. Sempreviva • \\ U. Giostra · A. Scrimieri
}

Received: 3 August 2007 / Accepted: 14 April 2008 / Published online: 8 May 2008

(C) Springer Science+Business Media B.V. 2008

\begin{abstract}
Within the canopy sub-layer (CSL), variability in scalar sources and sinks are known to affect flux-variance (FV) similarity relationships for water vapour $(q)$ and carbon dioxide $(C)$ concentrations, yet large-scale processes may continue to play a significant role. High frequency time series data for temperature $(T), q$ and $C$, collected within the CSL of an uneven-aged mixed coniferous forest in Lavarone, Italy, are used to investigate these processes within the context of FV similarity. This dataset suggests that MOST scaling describes the FV similarity function of $T$ even though the observations are collected in the CSL, consistent with other studies. However, the measured FV similarity functions for $q$ and $C$ appear to have higher values than their temperature counterpart. Two hypotheses are proposed to explain the measured anomalous behaviour in the FV similarity functions for $q$ and $C$ when referenced to $T$. Respired $\mathrm{CO}_{2}$ from the forest floor leads to large positive excursions in the $C$ time series at the canopy top thereby contributing significantly to both $C$ variance increase and $C$ vertical flux decrease-both leading to an anomalous increase in the
\end{abstract}

D. Cava $\cdot$ A. Scrimieri

CNR - Institute of Atmosphere Sciences and Climate, U.O. of Lecce, Lecce, Italy

G. G. Katul $(\varangle)$

Nicholas School of the Environment and Earth Sciences, Duke University, P.O. Box 90328, Durham, NC 27708-0328, USA

e-mail: gaby@duke.edu

G. G. Katul

Department of Civil and Environmental Engineering, Duke University, Durham, NC, USA

A. M. Sempreviva

Ris $\emptyset$ National Laboratory, Department of Wind Energy, Technical University of Denmark, Roskilde, Denmark

A. M. Sempreviva

CNR - Institute of Atmospheric Sciences and Climate, U.O. of Lamezia, Lamezia Terme, Italy

U. Giostra

Department of Environmental Science, University of Urbino, Urbino, Italy

A. Scrimieri

Material Science Department, University of Lecce, Lecce, Italy 
FV similarity function. For $q$, transport of dry air from the outer-layer significantly increases both the variance and the water vapour flux. However, the expected flux increase is much smaller than the variance increase so that the net effect remains an increase in the measured FV similarity function for water vapour above its $T$ counterpart. The hypothesis here is that identifying these events in the temporal and/or in the frequency domain and filtering them from the $C$ and $q$ time series partially recovers a scalar flow field that appears to follow FV similarity theory scaling. Methods for identifying both types of events in the time and frequency domains and their subsequent effects on the FV similarity functions and corollary flow variables, such as the relative transport efficiencies, are also explored.

Keywords Canopy turbulence - Carbon dioxide transport - Flux-variance similarity · Forest floor respiration · Outer-layer modulations · Scalar dissimilarity

\section{Introduction}

Flux-profile and flux-variance (FV) similarity theory and scaling behaviour of scalar variance remains critical for developing and testing footprint and plume dispersion models. However, little is known about such scaling within the roughness sub-layer of forested canopies, at least when compared to the atmospheric surface layer (ASL).

Over the past two decades, a large number of studies have shown that flux-profile and FV similarity functions for scalars such as temperature $(T)$ and water vapour concentration $(q)$ mainly differ due to source inhomogeneity at the ground (Thom et al. 1975; Garratt 1978; Raupach 1979; Raupach et al. 1979; Padro 1993; Kustas et al. 1994; Katul et al. 1995; Bink 1996; Bink and Meesters 1999; Andreas et al. 1998; Mölder et al. 1999; Lyons et al. 2001). However, even over a homogeneous surface, several studies did not find FV functions for $T$ to be identical to those for $q$ (De Bruin et al. 1993). Other studies suggested that some of the observed differences between FV similarity functions for $T$ and $q$ may be attributed to the active role of temperature in the turbulent kinetic energy (TKE) budget (Katul and Hsieh 1999). De Bruin et al. (1993) observed that when surface evaporation was sufficiently low, top-down processes related to entrainment were such that the local standard deviation of $q$ was no longer related to the local surface flux (Mahrt 1991a, b; Roth and Oke 1995; Asanuma et al. 2007). Similar conclusions were reported for the marine surface layer (Mahrt 1991a; Sempreviva and Gryning 2000; Katul et al. 2008). Hence, this lead a number of authors to conclude that higher-order statistics similarity relationships (such as the FV similarity functions) measured in the ASL are sensitive to modulations from non-local effects such as large-eddy convection and/or entrainment from the 'free atmosphere'. These non-local (hereafter referred to as 'outer-layer') modulations are likely to affect significantly the scalar variances, but less so vertical fluxes (Hogstrom 1990; Roth and Oke 1995; McNaughton and Laubach 1998; Hogstrom et al. 2002; McNaughton and Brunet 2002; Cullen et al. 2007). During daytime conditions, convective structures populate the outer layer (defined here as that part of the atmospheric boundary layer that extends well above the ASL but just below the capping inversion). These convective structures transport to the surface dry and cold air from the upper mixed layer (as observed in Roth and Oke 1995) or dry and warm air entrained from above the capping inversion. While much attention has thus far centered on the TKE budget and FV similarity functions for $T$ and $q$ (Hogstrom et al. 1989; Leclerc et al. 1990; Lamaud and Irvine 2006), there is growing interest in exploring FV similarity relationships for carbon dioxide concentration $(C)$, in addition to $T$ and $q$. Contemporary applications utilizing FV similarity functions for $C$ include, (1) evaluating components of the turbulent 
$\mathrm{CO}_{2}$ flux budget near the canopy top for testing higher-order turbulent closure models (Juang et al. 2006), (2) developing alternative gap-filling methods for estimating annual carbon budgets (Choi et al. 2004), (3) comparing turbulent transport efficiencies between $\mathrm{CO}_{2}$ and other scalars such as $T$ and $q$ to inspect similarities in the transfer pathways near the ground.

This last application received significant attention in both vegetated and urban canopy sub-layer (CSL) experiments. Several studies revealed that the standard relationships of Monin-Obukhov similarity theory (MOST) require correction factors when used inside the CSL (Thom et al. 1975; Garratt 1978, 1980, 1983; Mölder et al. 1999). In fact in the CSL, variability in $C, q$, and $T$ sources and sinks within the canopy are likely to influence FV similarity relationships as well as other second-order flow statistics. For example, when only leaf stomata control the mass transfer, the turbulent transport efficiency of $C$ and $q$ should be comparable in magnitude, and departures from this inequality may be used to assess respiratory contributions (Williams et al. 2007; Thomas et al. 2008). In urban environments, linkages between differences in car and house emissions of $C$ and release of $q$ by urban vegetation were captured by differences in transport efficiencies (Moriwaki and Kanda 2006). Still, non-local modulations originating from the outer layer may continue to play a significant role in scalar dissimilarity above both urban and vegetated canopies (De Bruin et al. 1993; Roth and Oke 1995; de Arellano et al. 2004; Moene et al. 2006; Górska et al. 2006). Recently, Moene et al. (2006) explored the influence of surface heterogeneity and of entrainment effects on the deviation from MOST for temperature, humidity and carbon dioxide concentration using observations made over a savannah landscape in Ghana (West Africa). They confirmed MOST scaling during wet soil moisture conditions and deviations from MOST scaling during dry soil moisture conditions, and attributed these departures to entrainment processes from the outer layer, consistent with Detto et al. (2008) for a semi-arid ecosystem in Sardinia (Italy). Roth and Oke (1995) attributed the scalar dissimilarity above an urban area, in part, to the influence of convective structures that extended well above the surface layer and originated in the outer layer or above the capping inversion.

Hence, further investigation on FV similarities within the CSL for these three scalars $(T, q$, and $C$ ) appears warranted to assess how the FV similarity functions are modified and whether large-scale processes within the outer-layer continue to play a significant role in scalar similarity relationships within the CSL. In this context, large-scale processes refer to processes originating from the outer layer or above the capping inversion with integral length scales much larger than the local mixing length within the ASL.

As a case study, the FV similarity functions (and corollary statistics such as the transport efficiencies and scalar correlations) for $T, q$ and $C$ are considered within the CSL above an alpine-forested site in Lavarone Italy, away from any major industrial or urban centre. The unique attributes of the site and the study period include, (1) cloud free conditions during much of the daytime, (2) sufficiently water stressed conditions so that latent heat fluxes $(L E)$ were much smaller than their sensible heat flux $(H)$ counterpart (enhancing dry convective conditions previously reported to produce outer-layer modulations in the ASL), and (3) source-sink relationships for $\mathrm{CO}_{2}$ and water vapour are significantly different in this stand. The main $q$ sources and $C$ sinks reside in the foliage and are controlled by leaf stomata. For $C$, however, there is an additional source due to forest floor respiration introducing significant dissimilarity in the $C$ versus $q$ sources and sinks. The forest floor evaporation for this dense and water stressed canopy is negligible compared to the latent heat flux from the canopy top. Hence, by using all three scalars here, the main turbulent mechanisms contributing to the anomalous behaviour in FV similarity functions within the CSL are investigated. Two 
hypotheses are proposed to explain the measured anomalous behaviour in the FV similarity functions for $q$ and $C$ when referenced to $T$. Respired $\mathrm{CO}_{2}$ from the forest floor is shown to lead to large positive excursions in the $C$ time series at the canopy top. This respiration contribution significantly amplifies the FV similarity functions during daytime conditions by reducing the net vertical carbon dioxide flux (i.e. smaller negative value) and by increasing the $C$ variance. On the other hand, for unstable conditions, outer-layer modulations to the CSL can affect the FV similarity function for $q$. Transport of dry air from the outer layer significantly increases both the $q$ variance and the latent heat flux consistent with other canopy turbulence studies (including urban). However, the expected flux increase is much smaller than the variance increase (De Bruin et al. 1993) so that the net effect remains an increase in the measured FV similarity function for water vapour above its classical behaviour.

Therefore, identifying these 'anomalous' events in the temporal and/or in the frequency domain and filtering them from the $C$ and $q$ time series might partially recover a scalar flow field that follows classical FV similarity theory. It should be noted that the analysis here does not consider the full range of possibilities known to induce anomalous scaling in FV similarity functions such as advective conditions (Kroon and De Bruin 1995; McNaughton and Laubach 2000; Assouline et al. 2008). However, the interplay between outer-layer processes and dissimilarity in canopy scalar sources and sinks, the focus here, remains a logical first step in any basic inquiry on FV similarity functions for carbon dioxide concentration within the CSL.

Unless otherwise stated, the following nomenclature is used: the longitudinal, lateral, and vertical coordinates are $x, y$, and $z$, respectively, and the instantaneous velocity components along these three directions are $u, v$, and $w$, respectively. An overbar indicates time averaging and a prime denotes a fluctuation from the time average. Because the analysis is conducted for the scalar statistics collected above the canopy, no spatial averaging is necessary.

\section{Theory}

Based on MOST for a stationary and planar homogeneous flow without subsidence, any dimensionless turbulence statistic depends on the atmospheric stability parameter, $\zeta=\frac{z-d}{L}$, where $z$ is the height above the ground, $d$ is the zero-plane displacement, and $L$ is the Obukhov length given by

$$
L=-\frac{u_{*}^{3} \bar{T}}{\kappa g \overline{w^{\prime} T^{\prime}}},
$$

where $\overline{w^{\prime} T^{\prime}}$ is the mean kinematic sensible heat flux, $\bar{T}$ is the mean air temperature, $\kappa=0.4$ is von Karman's constant, $g$ is the gravitational acceleration, and $u_{*}$ is the friction velocity given by

$$
u_{*}=\left({\overline{u^{\prime} w^{\prime}}}^{2}+{\overline{v^{\prime} w^{\prime}}}^{2}\right)^{1 / 4}
$$

where $u^{\prime}, w^{\prime}$, and $v^{\prime}$ are the turbulent fluctuations in the longitudinal, vertical, and lateral velocities, respectively. The turbulent standard deviation of any scalar $s, \sigma_{s}$, can be expressed as a function of $\zeta$ (Tillman 1972; Businger 1973)

$$
\frac{\sigma_{s}}{\left|s_{*}\right|}=\phi_{s}(-\zeta)
$$

where $s_{*}=\overline{w^{\prime} s^{\prime}} / u_{*}$ is a scalar concentration scale. The function $\phi_{s}(-\zeta)$ must satisfy two limits (De Bruin 1982; De Bruin et al. 1993, 1994; Albertson et al. 1995; Wesson et al. 2001): 
(1) In the neutral case, $-\zeta \rightarrow 0$ and $\phi_{s}(-\zeta)$ approaches a constant.

(2) In the free convection limit, $-\zeta \rightarrow \infty$ and $\sigma_{s} / s_{*}$ should become independent of $u_{*}$.

These two limits can be satisfied with an expression of the form

$$
\frac{\sigma_{s}}{s_{*}}=C_{1}\left(1-C_{2} \zeta\right)^{-1 / 3}
$$

where $C_{1}$ and $C_{2}$ are similarity constants.

For free convection conditions (e.g. $-\zeta>5$ ), Eq. 4 is well approximated by

$$
\frac{\sigma_{s}}{s_{*}} \approx C_{3}(-\zeta)^{-1 / 3}
$$

where $C_{3} \approx 0.99$ (corrected for $\kappa=0.4$ ) originally determined elsewhere (Wyngaard et al. 1971) and verified over a semi-arid area in the region called 'La Crau' in southern France (Kohsiek et al. 1993), over a uniform and flat and dry lakebed (Albertson et al. 1995), and for several canopies (Wesson et al. 2001). Although the $\phi_{S}(-\zeta)$ function was experimentally shown to be the same for $T, q$, and $C$ over a uniform wheat field (Ohtaki 1985), De Bruin et al. (1999) studied the correlation coefficient between $T$ and $q$ over a dry vineyard in Spain and concluded that if non-local effects are of the same order as local effects, $T$ and $q$ will be dissimilar.

The functions $\phi_{s}(-\zeta)$ for two scalars (e.g. $q$ and $C$ ) can be related to their transport efficiency ratios by

$$
\frac{\sigma_{c}}{\left|c_{*}\right|} \frac{\left|q_{*}\right|}{\sigma_{q}}=\frac{\phi_{c}(-\zeta)}{\phi_{q}(-\zeta)}=\frac{\sigma_{c} \overline{w^{\prime} q^{\prime}} / u_{*}}{\sigma_{q} \overline{w^{\prime} c^{\prime}} / u_{*}}=\frac{R_{w q}}{R_{w c}},
$$

where $R_{\mathrm{ws}}=\overline{w^{\prime} s^{\prime}} /\left(\sigma_{w} \sigma_{s}\right)$ is the correlation coefficient between vertical velocity and an arbitrary scalar concentration. If expression (5) is used to represent the FV similarity functions, then the ratio of the transport efficiency of the two scalars becomes the inverse ratio of the FV similarity constants.

\section{Experiment}

Much of the experimental set-up is described elsewhere (Marcolla et al. 2003; Cava et al. 2006), and only salient features most pertinent to the study objectives are repeated here for completeness. The experimental site is an uneven-aged mixed coniferous forest in Lavarone, Italy $\left(45.96^{\circ} \mathrm{N}, 11.28^{\circ} \mathrm{E} ; 1,300 \mathrm{~m}\right.$ above sea level). This site is part of a long-term $\mathrm{CO}_{2}$ flux monitoring initiative known as CarboEuroflux (Valentini et al. 2000). The canopy is about 28-30 m tall $\left(=h_{c}\right)$ and is primarily composed of Abies alba (70\%), Fagus sylvatica $(15 \%)$, and Picea abies (15\%), with a maximum leaf area index of $9.6 \mathrm{~m}^{2} \mathrm{~m}^{-2}$ when expressed as half of the total leaf area per unit ground.

The data used for the analysis were collected as part of a summertime intensive measurement campaign performed in 2000 (from August 10 to September 8). The micrometeorological tower was situated on a gently rolling plateau, selected to ensure homogeneous vegetation within at least $1 \mathrm{~km}$ distance in all directions, except for a $45^{\circ}$ sector in the south and southwest for which the vegetation extended uniformly some $300 \mathrm{~m}$ from the tower. The tower was equipped with five eddy-covariance flux instruments situated at 33, 25, 17.5, 11, $4 \mathrm{~m}$ from the forest floor. The turbulent velocity and sonic anemometer temperature were sampled at $20 \mathrm{~Hz}$ for the highest and the lowest levels by Gill R3 ultrasonic anemometers (Gill Instrument, 
Lymington, UK.). The water vapour and carbon dioxide concentration were sampled only at these two levels by the same data acquisition system using a LiCor 7500 open-path fast response infrared gas analyzer (IRGA) (LiCor Inc., Lincoln, NE, USA). Hence, the analysis here uses time series data collected at these two levels.

Half-hourly mean values of the main turbulence statistics were computed for each level following two coordinate rotations to ensure the mean lateral and vertical velocities were zero. These two rotations were needed because the interest here is not in the total mass transport but in how turbulent fluxes relate to turbulent scalar variances. The Webb-Pearman-Leuning correction (Webb et al. 1980; Detto and Katul 2007) was used to separate 'natural' fluctuations from fluctuations induced by 'external' effects (i.e. air temperature and water vapour concentration fluctuations) in the measured carbon dioxide and water vapour concentrations.

The analysis was performed on 19 days during daytime conditions (between 0900 and 1500 local time) resulting in 228 30-minute runs, while those exhibiting clear non-stationarity were discarded. The atmospheric stability conditions were classified based on $\zeta=\frac{z-d}{L}$, where $d \approx 0.75 h_{c}$ is the zero-plane displacement height for momentum and $L$ is measured at the canopy top. For some analyses (see Sect. 4.2), atmospheric stability conditions were not treated as a 'continuum' but clustered according to three classes: near neutral $(-0.1<\zeta<0)$; mildly unstable $(-0.8<\zeta<-0.1)$; and unstable $(\zeta<-0.8)$.

\section{Results}

The similarity between scalars and flux-variance MOST scaling is first tested above the top of the forested canopy $(z=32 \mathrm{~m})$, and possible causes of dissimilarity are investigated using quadrant analysis and conditional sampling methods. Observations of scalar patterns collected near the forest floor $(z=4 \mathrm{~m})$ are used as additional or 'satellite' signals for further confirmation that some events are not statistical artefacts but are large-scale and coherent.

\subsection{Flux-Variance Analysis}

The dimensionless standard deviations for temperature, water vapour, and carbon dioxide concentrations measured above the top of the forest $(z=32 \mathrm{~m})$ are plotted against $-\zeta$, shown in Fig. 1. Overall, the temperature data follow a typical MOST FV scaling described by Eq. 4 when $\mathrm{C}_{1}=2.3 \pm 0.1$ and $\mathrm{C}_{2}=9.5 \pm 0.5$ (the correlation coefficient $R=0.76$ ). These coefficients compared well with coefficients derived for the ASL $\left(C_{1}=2, C_{2}=9.5\right.$, as in Kaimal and Finnigan 1994). The error estimate of the model coefficients was derived from Monte-Carlo simulations by randomizing these two coefficients and only accepting combinations in which $R$ does not decrease with respect to its optimized value $(R=0.76)$. The measured FV similarity functions for the other two scalars exhibit significant scatter.

A number of studies, reviewed in the Appendix, have pointed out to the possible spurious functional relationship between measured $\sigma_{s} / s_{*}$ and measured $\zeta$ because $u_{*}$ appears in the dependent variable (through $s_{*}$ ) and the independent variable (through $L$ ). The validity of the derived relationships has been tested (see Appendix) to assess the impact of such spurious correlations arising from the fact that $u_{*}$ variability affects both dependent and independent variables.

Sensible heat generally appeared to be transported more efficiently than carbon dioxide or water vapour (Fig. 2), in agreement with Katul et al. (1995), Roth and Oke (1995), Katul and Hsieh (1999), Lamaud and Irvine (2006), Moriwaki and Kanda (2006). However, the interest here lies in the variability in the correlation coefficients of water vapour and carbon 
Fig. 1 Dimensionless standard deviation of (a) temperature $(T)$, (b) water vapour concentration (q) and (c) $\mathrm{CO}_{2}$ concentration $(C)$, sampled above the canopy top $(z=32 \mathrm{~m})$, versus the stability parameter $-\zeta$. Black stars refer to raw measurements, and grey full circles refer to data with 'anomalous events' filtered out from the $q$ and $C$ time series. The black dashed lines represent the experimental similarity functions $\sigma_{s} / s_{*}=$ $C_{1}\left(1-C_{2} \zeta\right)^{-1 / 3}$, where $C_{2}=9.5$ for all of the three scalars, whereas $C_{1}=2.3,3.4$ and 2.8 for $T, q$, and $C$, respectively. The black dotted lines represent the similarity functions for free convection regime $\sigma_{s} / s_{*}=C_{3}(\zeta)^{-1 / 3}$ where $C_{3}=C_{1} C_{2}^{-1 / 3}$
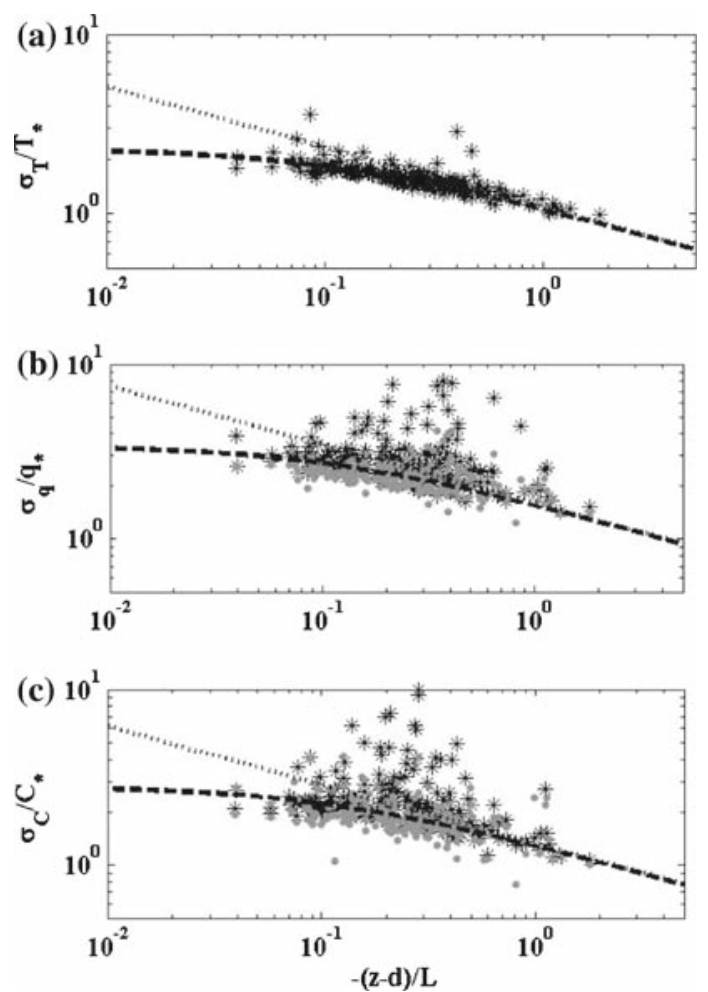

dioxide (Fig. 3); it appears that the mode of this correlation is lower than unity (in absolute value) and the scatter is as significant as that of heat to water vapour comparisons.

In situations similar to those under investigation, the different behaviour of the $T$ and $q$ scalars may be partially explained by the active role of temperature in the transport (Katul and Hsieh 1999). However, this argument fails to explain the dissimilarity between $q$ and $C$, especially given the fact the $q$ is generally low and can be treated as a passive scalar. To explore the time scales at which these dissimilarities originate, the scalar spectra (for variances) and cospectra are considered next.

\subsection{Spectra and Cospectra}

Spectral and cospectral analysis is used to explore the main mechanisms (i.e. phenomena and associated scales) affecting variances and vertical fluxes of these three scalars for different stability regimes. To minimize statistical uncertainty due to possible intermittent contributions by large-scale motions comparable to the boundary-layer depth, the spectra and cospectra are computed using 5-h (from 1,000 to 1,500) windows for the three stability classes discussed in Sect. 3. To reduce the number of data points involved in the fast Fourier transform computation, the sampling frequency was reduced from $20 \mathrm{~Hz}$ to $2 \mathrm{~Hz}$. The contribution of these high frequencies to both variances and fluxes were found to be small $(<10 \%)$. The ensemble averaged spectra and cospectra for the three atmospheric stability classes are, respectively, plotted in Figs. 4 and 5. 
Fig. 2 Relative efficiency of (a) $T$ and $q$, (b) $T$ and $C$, and (c) $q$ and $C$ above the canopy top $(z=32 \mathrm{~m})$ versus the stability parameter $-\zeta$. Black stars and grey full circles are defined in Fig. 1
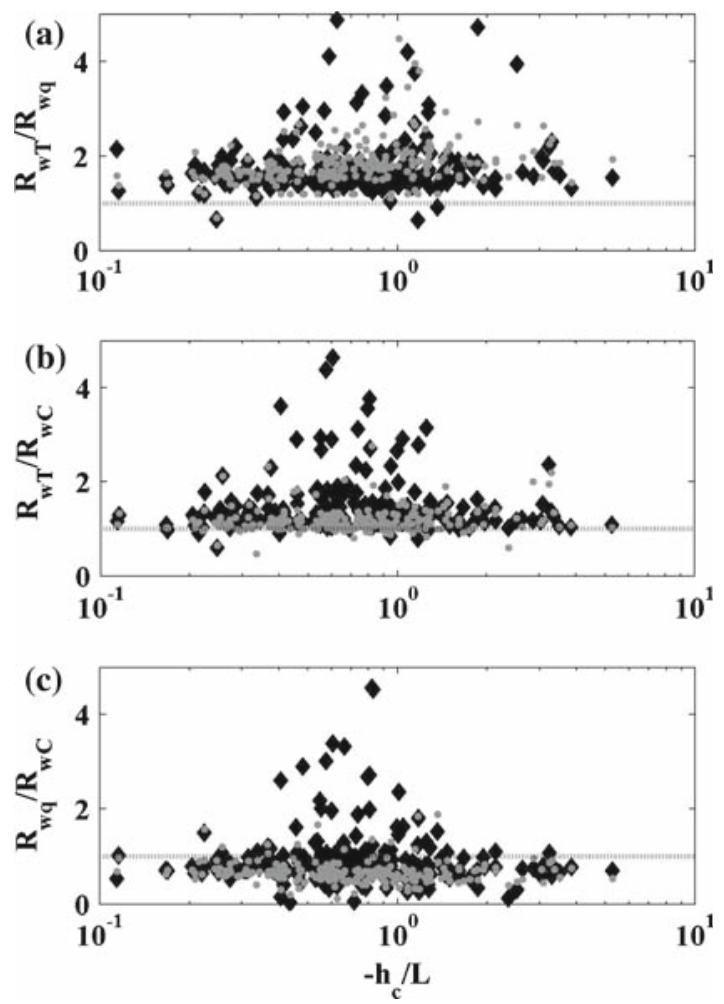

The spectral energy allows detection of scales that cause deviations of normalized variances from their ASL states (Fig. 4). The spectrum of the vertical velocity component (computed for reference) peaks at a scale consistent with the shear production length scale near the canopy top (Raupach et al. 1996; Finnigan 2000; Poggi et al. 2004), and appears insensitive to atmospheric stability variations consistent with other studies (Brunet and Irvine 2000). The spectrum of $T$ exhibits similar behaviour to the $w$ spectrum for near-neutral conditions, but as unstable atmospheric stability conditions are approached, more of the spectral energy contribution resides at lower frequencies. In the case of $C$, energy remains mainly concentrated at canopy scales, but the effect of increased atmospheric stability is more pronounced in 'distributing' energy across lower frequencies (when compared to $w$, for example). The water vapour variance exhibits the strongest dependence on atmospheric stability and, in particular, under convective conditions much of the energy resides in the low-frequency range consistent with boundary-layer scale eddies.

The cospectra (Fig. 5) show that canopy scales dominate the mass and momentum transport, with boundary-layer eddies contributing much less to scalar fluxes when compared to their variance counterpart (i.e. they appear much less active in mass transport). However, their contribution increases as the flow becomes more convective, mainly for $T$ and $q$. Contributions from scales commensurate with the boundary-layer height appear not to modify much the $\mathrm{CO}_{2}$ fluxes probably because carbon dioxide transport at the top of the atmospheric boundary layer is not appreciable given that the Lavarone site is remote from any major industrial or urban centre. 
Fig. 3 Same as Fig. 2 but for the correlation coefficient between (a) $T$ and $q$, (b) $T$ and $C$, and (c) $q$ and $C$. Black stars and grey full circles are defined in Fig. 1
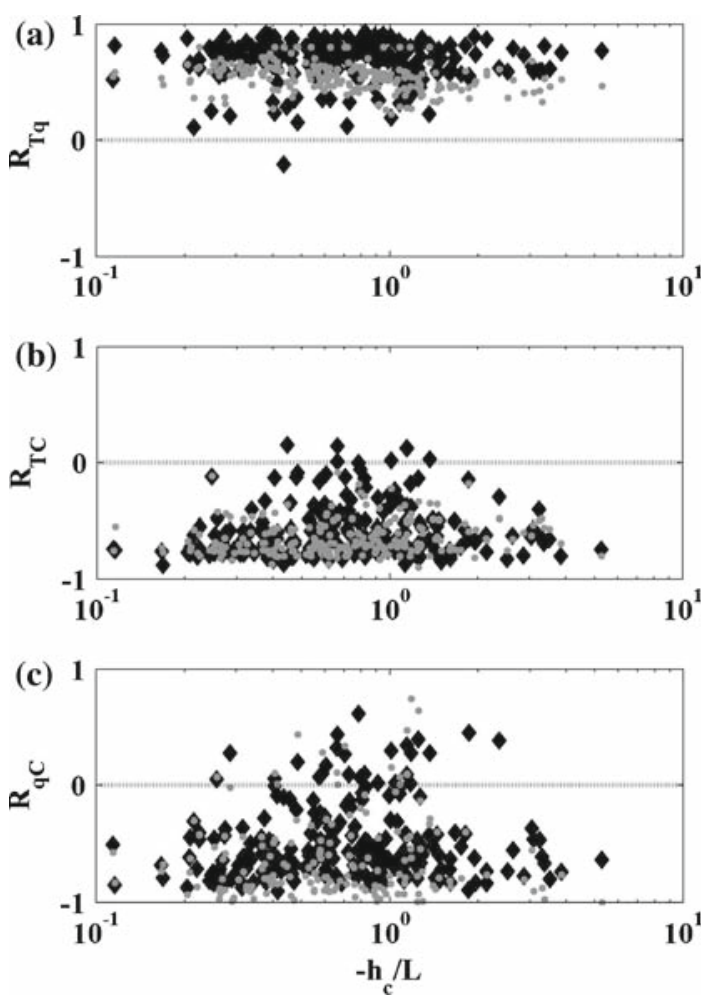

The analysis here demonstrates that large scales originating from the outer-layer, comparable in size with the atmospheric boundary-layer (ABL) depth, do contribute to CSL fluxes and variances, but this contribution is asymmetric with regards to the three scalars (especially $q$ ). Hence, the FV similarity may be 'modified' from their ASL scaling by such large-scale phenomena (especially $q$ ), though the persistent contribution of canopy-scale eddies to carbon dioxide transfer appears suggestive of other alternatives, such as forest source/sink dissimilarity within the canopy (Williams et al. 2007). Two hypotheses are proposed here to explain the anomalous behaviour of FV similarity functions for $q$ and $C$ in the CSL when compared to $T$ :

1. For $\mathrm{CO}_{2}$, the respiration from the forest floor, often identified by ejection events leading to large positive excursions in the $C$ time series at the canopy top, contributes significantly to both $\mathrm{CO}_{2}$ variance and flux. This contribution tends to amplify departure from the ASL similarity scaling because ejected air parcels reaching the canopy top reduce the $\mathrm{CO}_{2}$ flux (i.e. smaller negative value) and increase the $\mathrm{CO}_{2}$ variance (thereby increasing the FV similarity function).

2. For $q$, transport of dry air from the outer-layer significantly increases the variance and the flux. However, as evidenced by spectra and cospectra, the flux increase is much smaller than the variance increase so that the net effect remains an increase in the measured FV similarity function above that predicted by MOST scaling.

Hence, the identification of these events and their filtering from the $C$ and $q$ series may partially recover a scalar flow field that follows MOST similarity scaling. Methods for identifying 

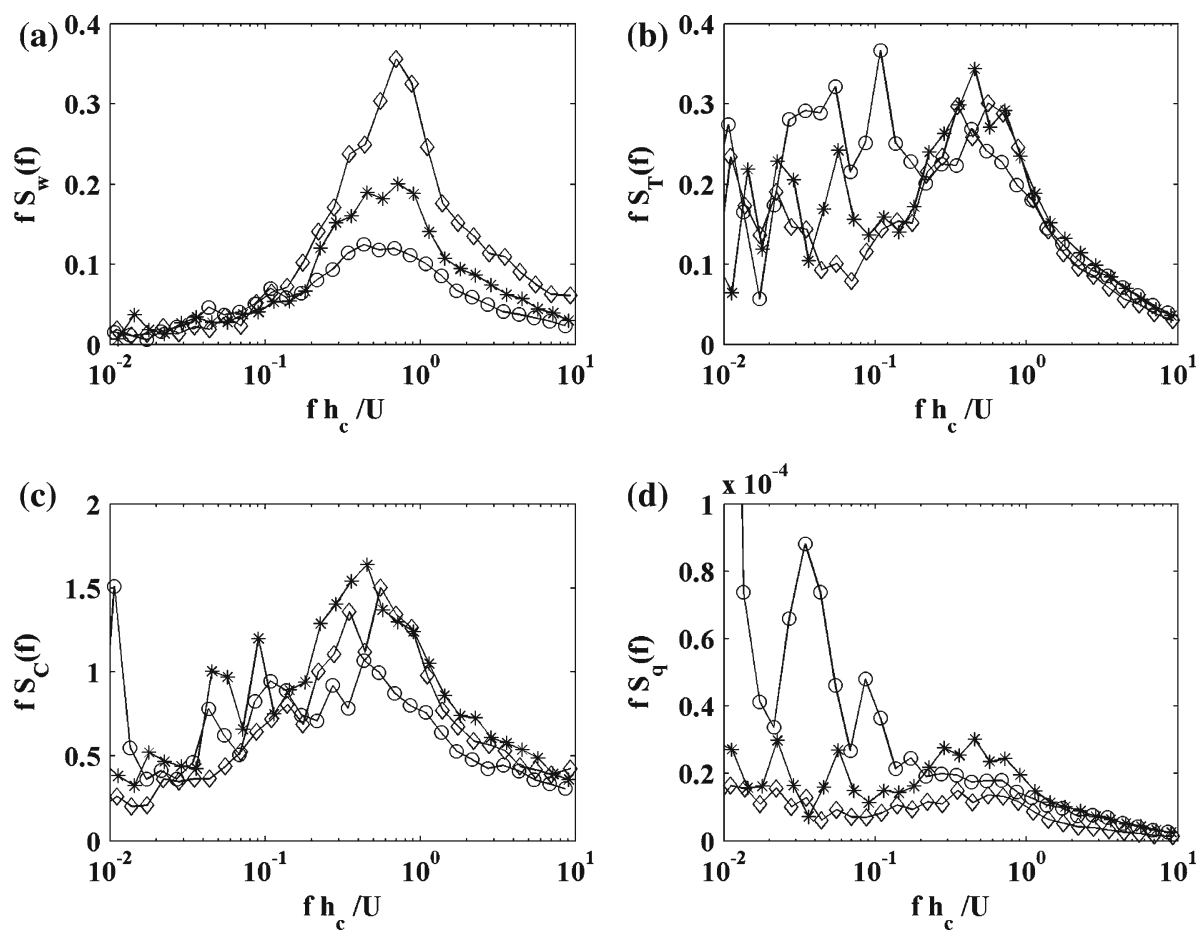

Fig. 4 Ensemble averaged spectra of (a) vertical velocity component $(w),(\mathbf{b}) T$, (c) $C$ and (d) $q$, sampled above the canopy top $(z=32 \mathrm{~m})$, versus normalised frequency $\left(f h_{c} / U\right)$. Different symbols refer to the three stability classes defined in Sect. 3: diamonds (near-neutral), stars (mildly unstable), and circles (unstable)

both types of events and their subsequent effects on the FV similarity functions are explored next.

\subsection{Identification of Events Causing Anomalous FV Scaling}

A reference case is shown in Fig. 6 for near-neutral conditions $(\zeta=-0.1)$ that demonstrates typical canopy turbulence features, i.e. organized ramps, unperturbed by any significant contribution from the forest floor respiration or any large-scale motion (such as outer-layer modulations). Quadrant analyses of data sampled above the canopy top for this reference case are shown in Fig. 7. The canonical features (e.g. spread along the main quadrant-forming axes) are used in the subsequent analysis as a 'reference' for identification of anomalous events. In the quadrant analysis, heat is used as a 'reference' scalar because its measured FV similarity function in the CSL is consistent with MOST scaling (Fig. 1). The time series during this reference period, collected near the forest floor, are shown in Fig. 6. In the detection of the anomalous events, the comparison of the scalar time series sampled at these two levels is used as an independent check that anomalous perturbations are not statistical artifacts but coherent events detected at both levels.

\subsubsection{Identification of Respiration Events}

Figure 8 shows a sample time series collected near the canopy top and at the lowest level. The canopy-top level exhibits large excursions in $\mathrm{CO}_{2}$ concentration during ejection events 

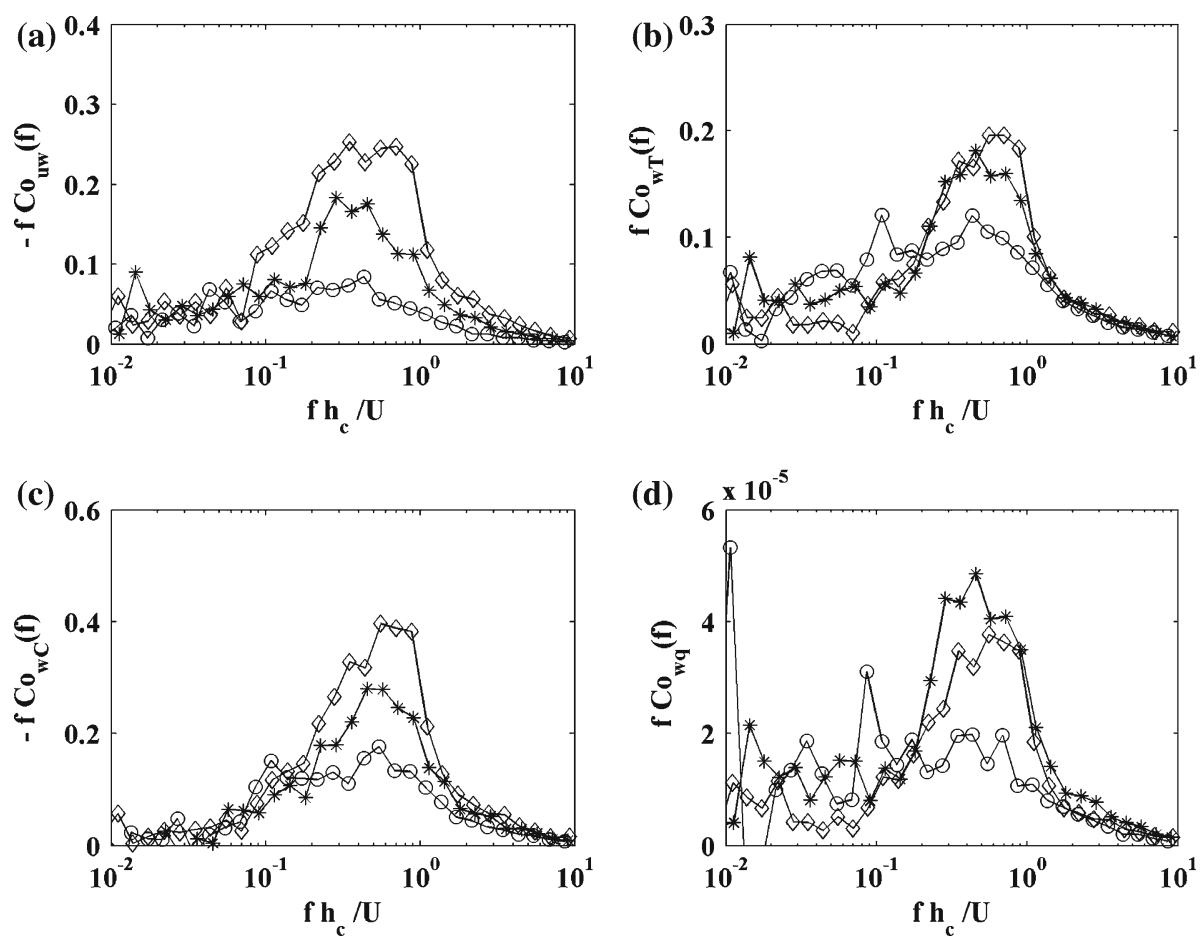

Fig. 5 Same as Fig. 4 but for the ensemble averaged cospectra of (a) momentum flux $\left(\overline{u^{\prime} w^{\prime}}\right)$, (b) sensible heat flux $\left(\overline{w^{\prime} T^{\prime}}\right),(\mathbf{c}) \mathrm{CO}_{2}$ flux $\left(\overline{w^{\prime} C^{\prime}}\right)$ and $(\mathbf{d})$ water vapour flux $\left(\overline{w^{\prime} q^{\prime}}\right)$

(associated with forest floor $\mathrm{CO}_{2}$ respiration). The corresponding $\mathrm{C}$ series collected at the lowest level clearly identifies respiration activity originating from the forest floor. Note the inverse ramp behaviour at the canopy top during these respiration events, connected with a change in the sign of the local flux (i.e. positive $\mathrm{CO}_{2}$ flux during these events). Hence, it is clear that such intense inverted ramps affect both the variance and the $\mathrm{CO}_{2}$ flux. The inverse ramp duration appears comparable to the other canopy ramps in the time series. For the other two scalars, these ejection events do not 'imprint' any particular ramp-like feature and do not appreciably contribute to the scalar variance. Hence, the dissimilarity in the FV functions of $\mathrm{CO}_{2}$ when compared to $q$ or $T$ may be partially explained by these respiration-ejection events, and it can also be hypothesized that the same process may affect the $q$ time series in a similar way in open canopies with a wet forest floor (for example, after a rain event).

The signature of such ramps in the quadrant analysis is illustrated in Fig. 9, which shows the major anomalous behaviour in quadrant 1 when compared to its counterpart for the reference case (Fig. 7). Clearly, this anomalous behaviour is connected with an ejection (or updraft) phase $\left(w^{\prime}>0\right)$. To characterize statistically this anomalous behaviour of $\mathrm{CO}_{2}$ fluctuations, these events have been automatically identified by a 'quadrant edge-detection' method, and Fig. 9 shows an example of how this method identifies 'anomalous' fluctuations. The temporal occurrence of events residing above the line connecting the edges of quadrant 1 for updraft motions (i.e. see the grey line connecting points $T^{\prime}=0$ and maximum $C^{\prime}$ and $C^{\prime}=0$ and maximum $T^{\prime}$ ) is first identified. By discarding these events, the quadrant analysis collapses back to the reference series in Fig. 7. The grey line in Fig. 9 highlights the detected anomalous 

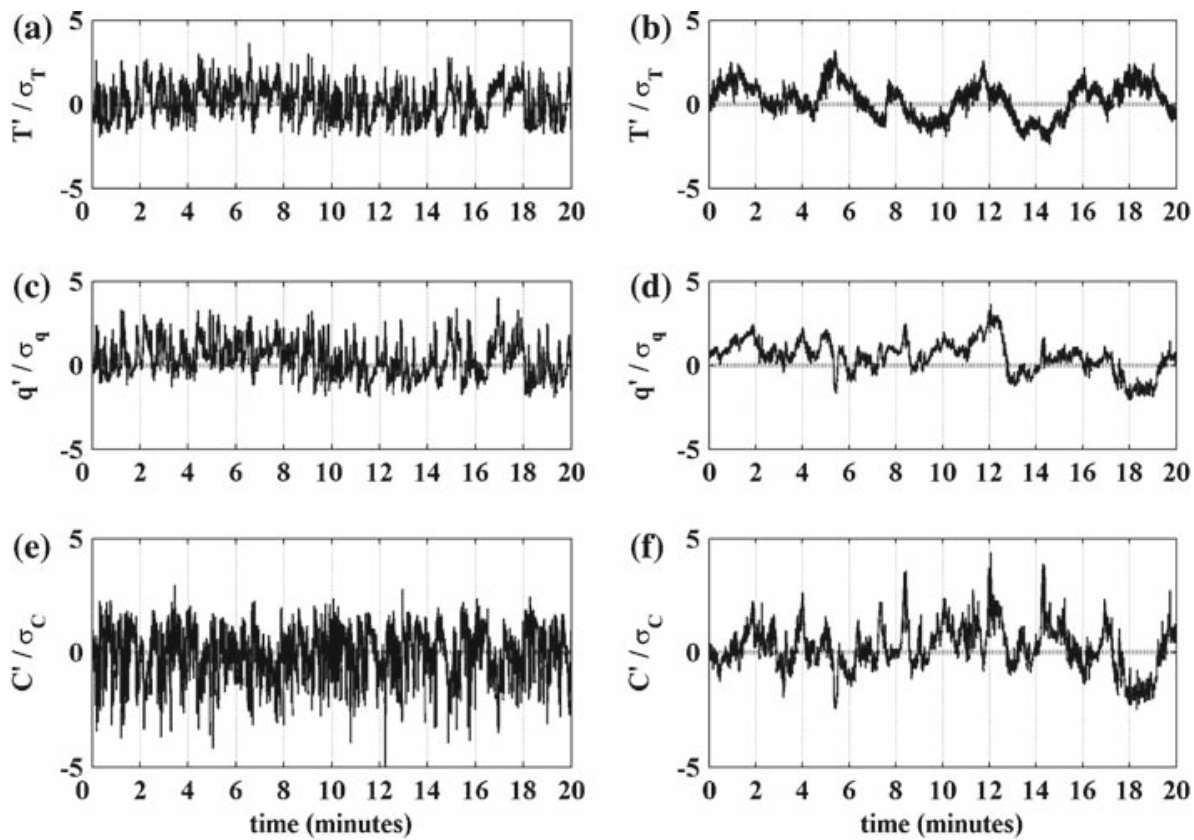

Fig. 6 Example time series of normalised (a) $T^{\prime}$, (c) $q^{\prime}$, and (e) $C^{\prime}$, sampled above the canopy top $(z=32 \mathrm{~m})$, for near-neutral conditions $(-\zeta=0.1)$. The same variables sampled near the forest floor $(z=4 \mathrm{~m})$ are also shown in (b), (d) and (f), respectively. The sample time series were collected on August 16, 1430-1450 local time. Above the canopy top the values of sensible heat flux, latent heat flux, and $\mathrm{CO}_{2}$ flux were $717 \mathrm{~W} \mathrm{~m}^{-2}$, $248 \mathrm{~W} \mathrm{~m}^{-2}$, and $-1.16 \mathrm{mg} \mathrm{m}^{-2} \mathrm{~s}^{-1}$, respectively; while near the forest floor they were $8 \mathrm{~W} \mathrm{~m}^{-2}, 13 \mathrm{~W} \mathrm{~m}^{-2}$, and $0.18 \mathrm{mg} \mathrm{m}^{-2} \mathrm{~s}^{-1}$, respectively

ramps by this method and it is suggestive of good detection skills, while Fig. 10 shows the histogram of the duration of the detected ramps via this scheme both in seconds and in terms of reduced frequency $\left(f h_{c} / U\right)$. Note that the duration of the ramps appears consistent with canopy scales, indirectly confirming the adequacy of this edge-detection method.

Furthermore, the impact of these anomalous respiration events on both the $\mathrm{CO}_{2}$ concentration standard deviation and vertical flux are explored for each 30-min run. Figure 11 shows that, as the frequency of occurrence of these events increases, the measured FV similarity function increases proportionately above its ASL value. When these events are filtered out and the fluxes and variances are re-computed, the resulting FV similarity functions appear less scattered and resemble in scaling the FV similarity functions for the ASL (as shown in Fig. 1c, grey points).

\subsubsection{Identification of Outer-Layer Modulation Events}

Figure 12 shows an example of a large and intense ramp in the $q^{\prime}$ signal in which a dry air event swept the canopy top and penetrated down to the forest floor. The excursions in humidity here are large and negative, and the duration of this anomalous ramp is about 6 minutes. This duration is much larger than expected for canopy turbulence and indicates that the anomalous ramp in the water vapour fluctuations must be related to outer-layer processes. Time series traces of $T^{\prime}$ and $q^{\prime}$ reported for an urban canopy (Roth and Oke 1995) show similar 'anomalous' ramps with the same signs and with comparable sizes, and 

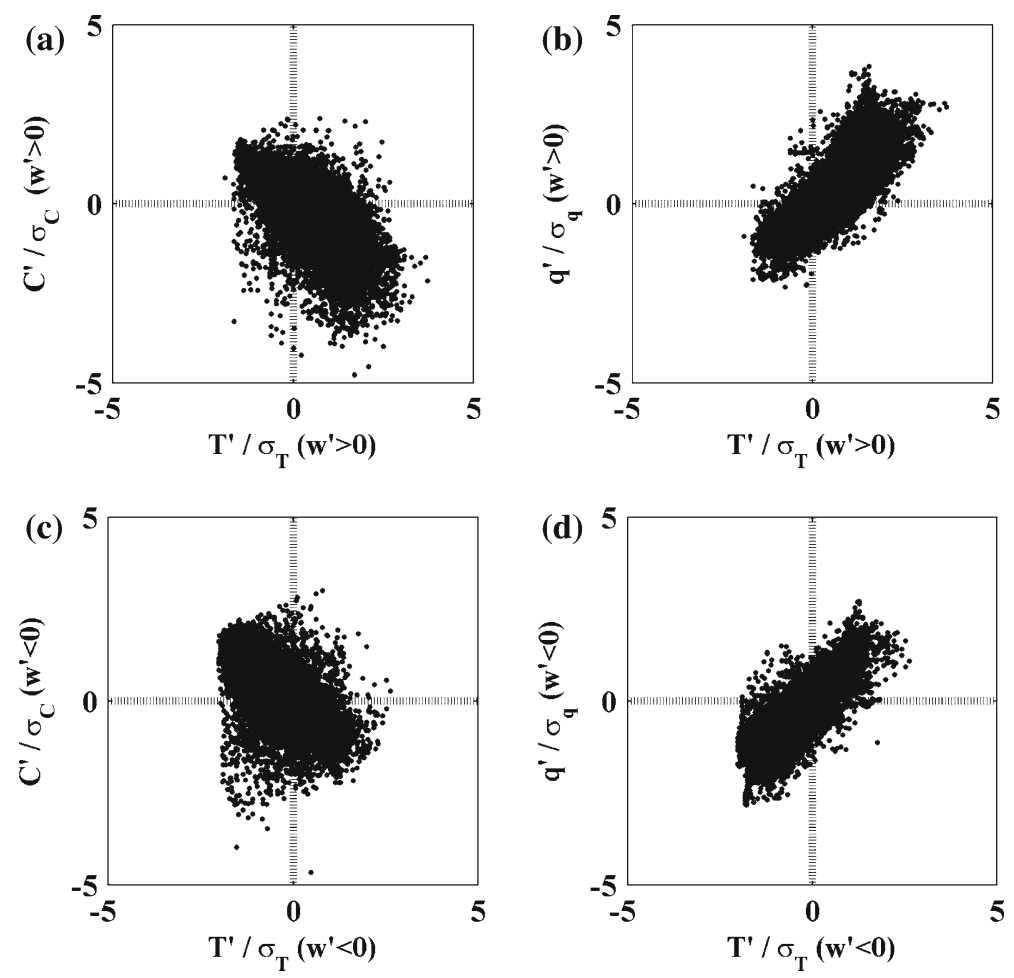

Fig. 7 Quadrant analysis of normalised $C^{\prime}$ versus $T^{\prime}$, conditioned on the basis of occurrence of (a) ejection events or updrafts $\left(w^{\prime}>0\right)$, and of (c) sweeping events or downdrafts $\left(w^{\prime}<0\right)$. The same analysis for $q^{\prime}$ versus $T^{\prime}$ is shown in (b) and (d). Data are relative to the time series collected above the canopy top shown in Fig. 6

Roth and Oke (1995) attributed the ramps to the passage of large rising thermals followed by cold and dry downdrafts from the outer layer. In this urban canopy study, the anomalous ramp duration ranged from $4 \mathrm{~min}$ to $6 \mathrm{~min}$, or $800 \mathrm{~m}$ to $1,200 \mathrm{~m}$ spatial scale, using a mean wind speed near the ground of about $3.5 \mathrm{~m} \mathrm{~s}^{-1}$. For the Lavarone site, this anomalous ramp duration is about $6 \mathrm{~min}$ and with a mean wind speed of $2 \mathrm{~m} \mathrm{~s}^{-1}$ leads to a length scale of about $720 \mathrm{~m}$. Roth and Oke (1995) also provided a phenomenological explanation for their anomalous ramp using a conceptual diagram, which has been extended in Fig. 13 to include $C$; variations in fluxes, concentrations, and two-scalar correlations are shown as well. In Fig. 13, dry and cold air originating from the outer layer is swept down and contributes to strong positive correlations between $T$ and $q$ in the CSL near the canopy top. However, the strength of this correlation is larger than the correlation originating from within the canopy via ejection events. The weaker correlation between $T$ and $q$ near the surface is mainly due to the dissimilarity in sources and sinks of $q$ and $T$ (Williams et al. 2007), so these anomalous events from the outer layer tend to strengthen the correlations between $T$ and $q$ while dissimilarity in sources and sinks within the canopy tend to weaken this correlation. Furthermore, the anomalous event affects both the vertical flux and variance of $q$, but less so for $T$ (consistent with the spectra and cospectra already reported in Figs. 4 and 5). For $C$, the signature of the anomalous ramp is also evident, but the magnitude of the $C$ excursions induced by this ramp is comparable to the background turbulence. The covariance between 

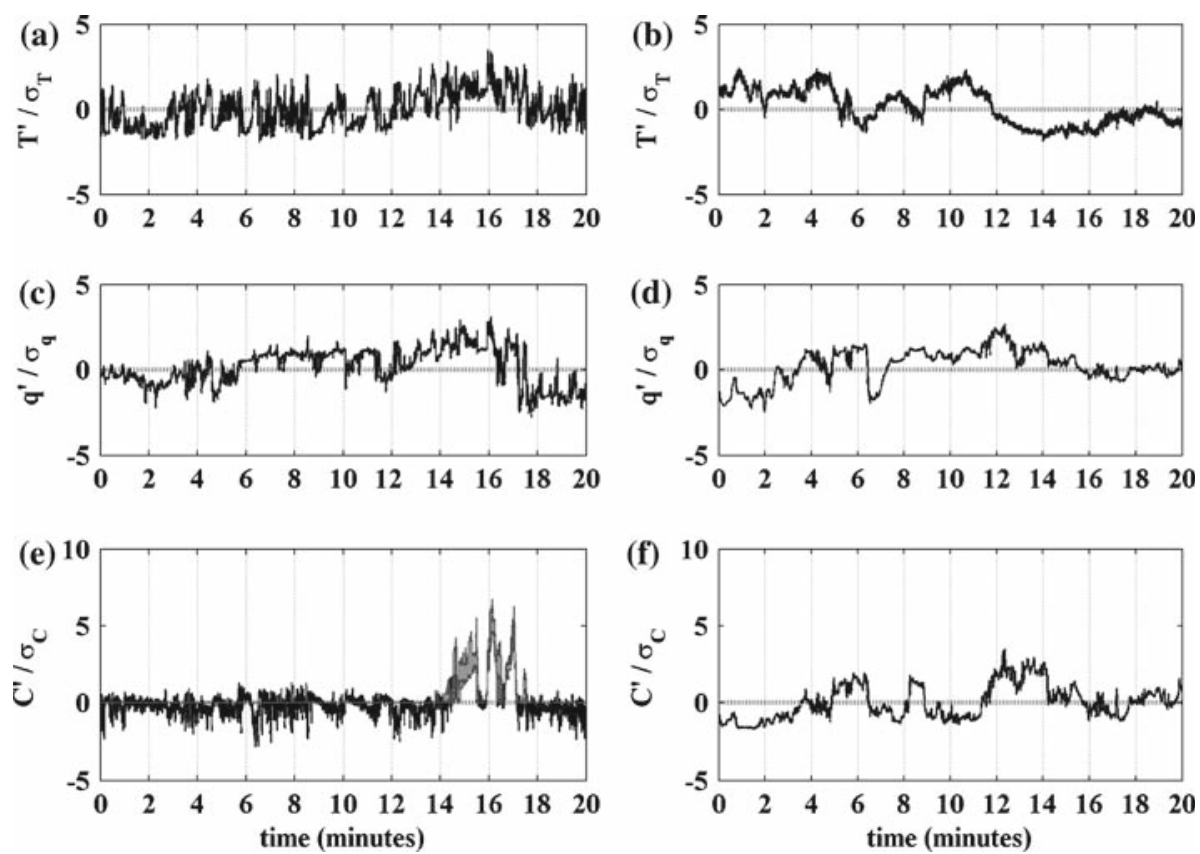

Fig. 8 Example time series of normalised (a) $T^{\prime}$, (c) $q^{\prime}$, and (e) $C^{\prime}$, sampled above the canopy top $(z=32 \mathrm{~m})$, showing large positive excursions in $C^{\prime}$ due to ejection events connected with forest floor respiration. The same variables sampled near the forest floor $(z=4 \mathrm{~m})$ are shown in $(\mathbf{b}),(\mathbf{d})$ and $(\mathbf{f})$, respectively for reference. The sample time series were collected on August 24, 1210-1230 local time. The atmospheric stability was $(-\zeta=0.5)$. Above the canopy top the values of sensible heat flux, latent heat flux, and $\mathrm{CO}_{2}$ flux were, respectively, $677 \mathrm{~W} \mathrm{~m}^{-2}, 216 \mathrm{~W} \mathrm{~m}^{-2}$, and $0.07 \mathrm{mg} \mathrm{m}^{-2} \mathrm{~s}^{-1}$; while near the forest floor they were, respectively, $-7 \mathrm{~W} \mathrm{~m}^{-2}, 34 \mathrm{~W} \mathrm{~m}^{-2}$, and $0.35 \mathrm{mg} \mathrm{m}^{-2} \mathrm{~s}^{-1}$. The grey line in (e) shows the result of the quadrant edge-detection method for discriminating respiration events when applied to the selected period (cf Fig. 9a)
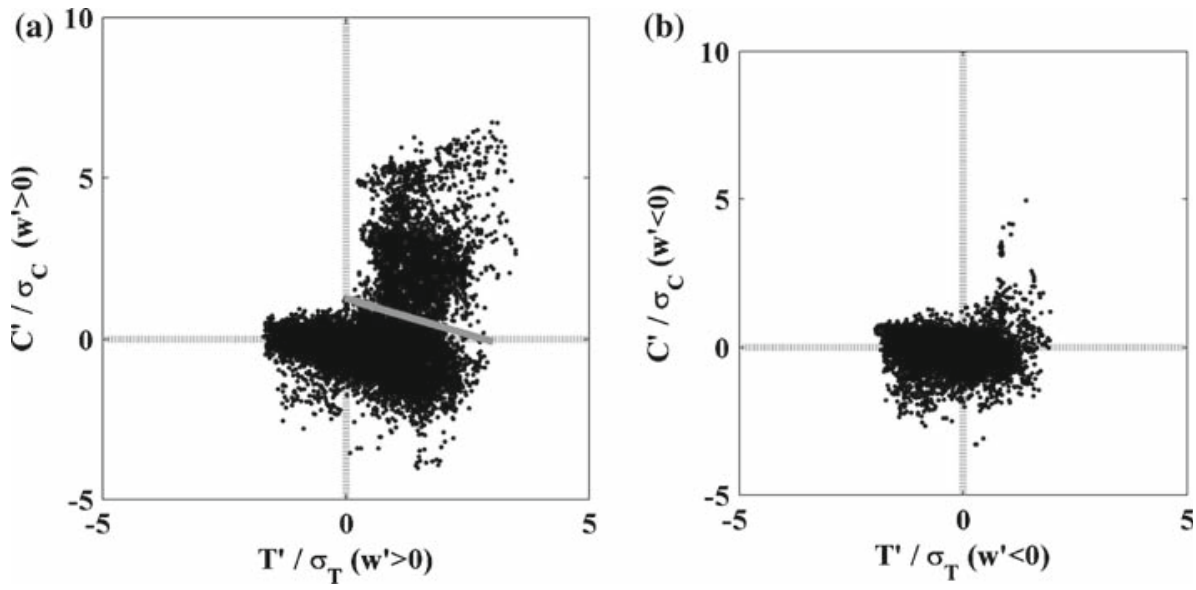

Fig. 9 Quadrant analysis of normalised $C^{\prime}$ versus $T^{\prime}$, conditioned on the basis of occurrence of (a) ejection events or updrafts $\left(w^{\prime}>0\right)$ and of (b) sweeping events or downdrafts $\left(w^{\prime}<0\right)$. Data are relative to the time series collected at the top of the canopy shown in Fig. 8. The grey line in (a) shows the result of the quadrant edge-detection method for discriminating respiration event, applied to the selected period (cf Fig. 8e) 

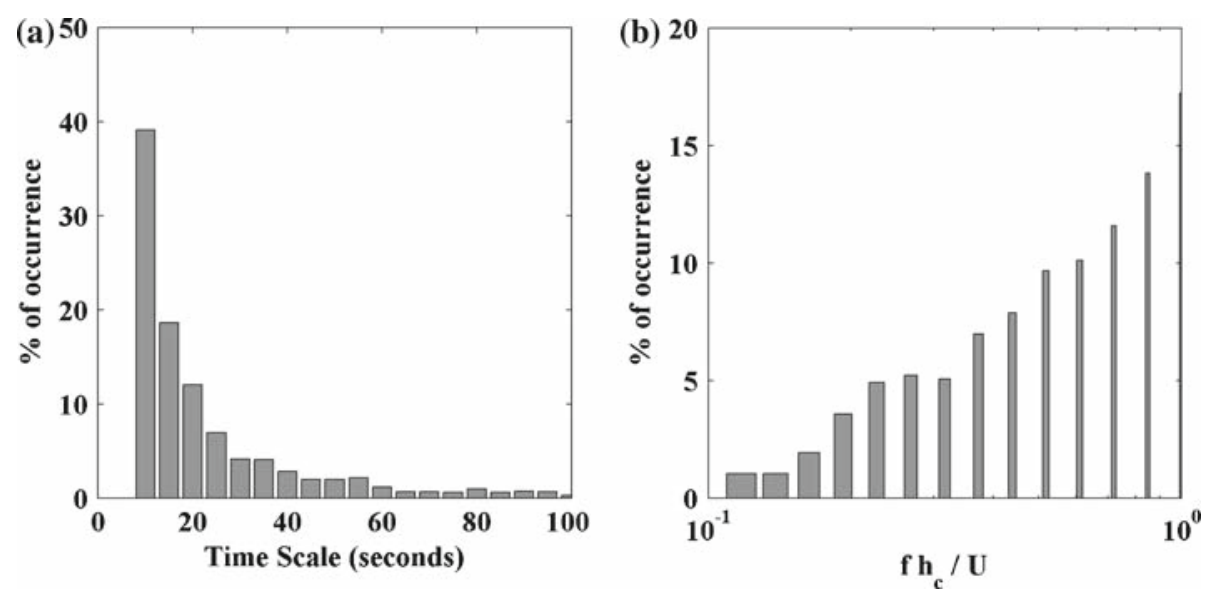

Fig. 10 Histogram of (a) the time scale duration and of (b) the normalised frequency $\left(f h_{c} / U\right)$ corresponding to these respiration events discriminated by the quadrant edge-detection method
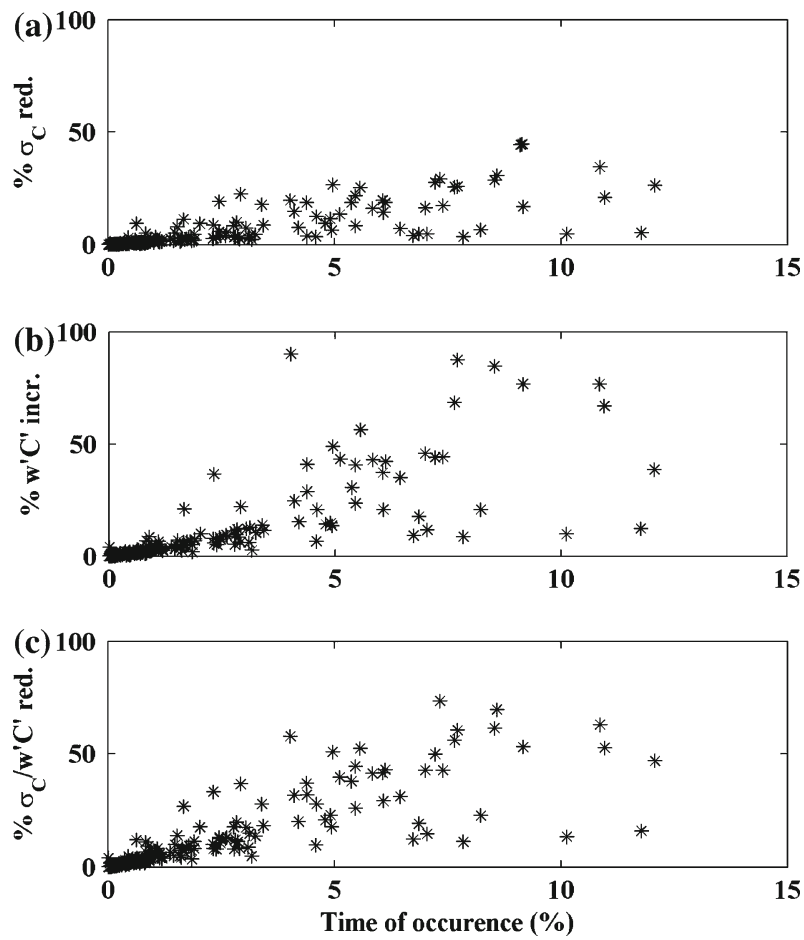

Fig. 11 Scatter plot of (a) reduction (\%) in $\sigma_{C},(\mathbf{b})$ increase (\%) in the $\overline{w^{\prime} C}$ and (c) reduction (\%) in $\sigma_{C} / \overline{w^{\prime} C /}$, after discarding the anomalous events related to the forest floor respiration versus their time of occurrence $(\%)$ in the 30-min time series 

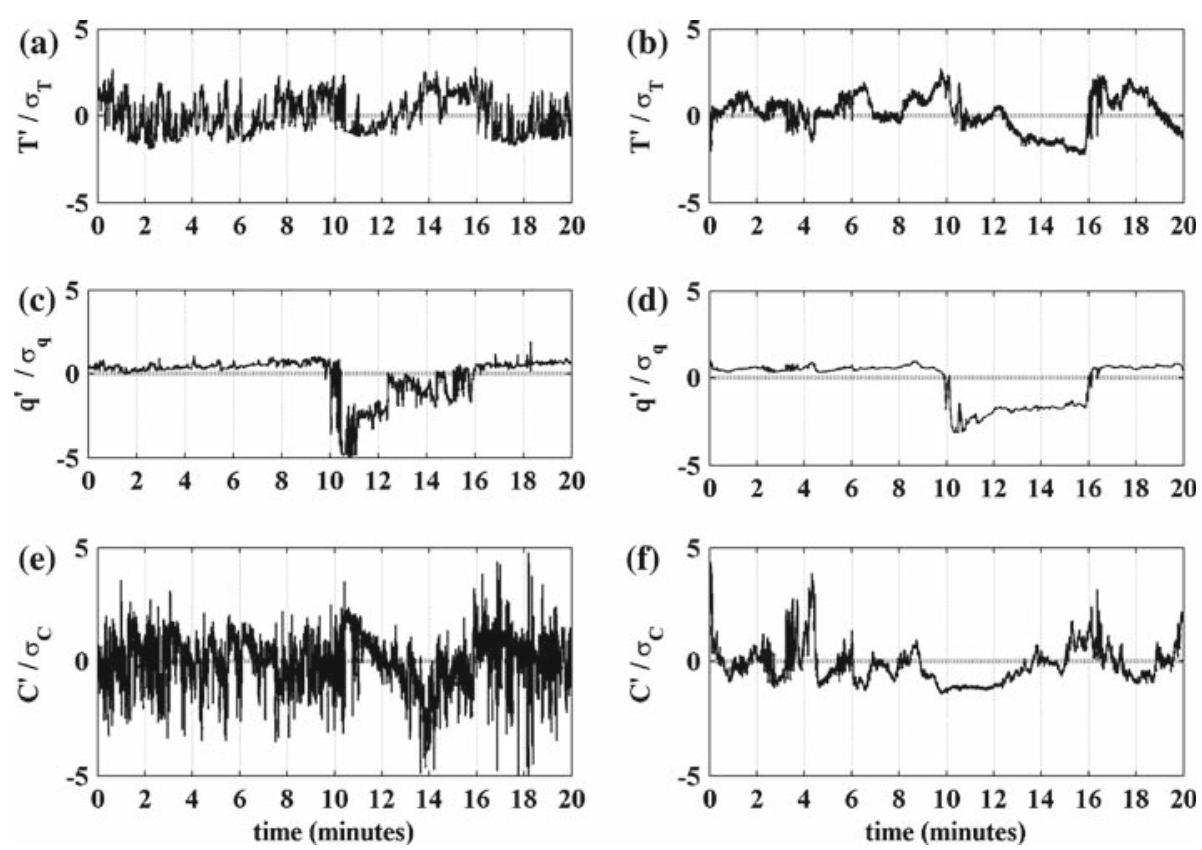

Fig. 12 Example time series of normalised (a) $T^{\prime}$, (c) $q^{\prime}$, and (e) $C^{\prime}$, sampled above the canopy top $(z=32 \mathrm{~m})$, showing large excursions in $q^{\prime}$ due to a downdraft event connected with large-scale outer-layer modulations. The same variables sampled near the forest floor $(z=4 \mathrm{~m})$ are shown in (b), (d) and (f), respectively. The sample time series were collected on August 20, 1210-1230 local time. The atmospheric stability was $-\zeta=0.3$. Above the canopy top the values of sensible heat flux, latent heat flux, and $\mathrm{CO}_{2}$ fluxes were, respectively, $677 \mathrm{~W} \mathrm{~m}^{-2}, 203 \mathrm{Wm}^{-2}$, and $-0.51 \mathrm{mg} \mathrm{m}^{-2} \mathrm{~s}^{-1}$; while near the forest floor they were, respectively, $-11 \mathrm{~W} \mathrm{~m}^{-2}, 18 \mathrm{~W} \mathrm{~m}^{-2}$, and $0.27 \mathrm{mg} \mathrm{m}^{-2} \mathrm{~s}^{-1}$

$C$ and $q$ becomes more negative due to these anomalous sweeps, but the overall contribution to the vertical $\mathrm{CO}_{2}$ fluxes and the $\mathrm{CO}_{2}$ variance is not appreciable. The contribution of this anomalous ramp to correlations between $C$ and $q$ remains clearly discernable, as shown in Fig. 13. In short, these anomalous ramps affect the correlation between $C$ and $q$ and the FV similarity function for $q$ but not the FV similarity function for $C$.

Quadrant analysis (Fig. 14) further confirms that this main event is a large-scale sweep (in quadrant 3) detected at both levels. Because the smaller canopy ramps are superimposed on this event, its signature also appears in the ejection phases. This ejection contribution becomes problematic for any automatic detection in the time domain (via quadrants) because of the superposition of canopy ramps. Hence, for these cases, a frequency cut-off has been chosen that takes advantage of the time-scale separation (4-6 min for the anomalous ramps versus tens of seconds for canopy turbulence). The reduced frequency cut-off ( $\left.f h_{c} / U=0.1\right)$ was chosen based on the shape of the vertical velocity spectrum (Fig. 4) and the momentum flux cospectrum (Fig. 5). These two figures suggest that canopy turbulence does not significantly affect variances and momentum fluxes when the reduced frequency is smaller than 0.1 . Hence, when the $q$ spectra and cospectra are 'high-pass filtered' on the basis of this reduced frequency cut-off, the resulting FV similarity function resembles in scaling the FV similarity functions for the ASL (see Fig. 1b, grey points). Furthermore, the scatter in the FV similarity functions derived from the filtered series is significantly reduced. 


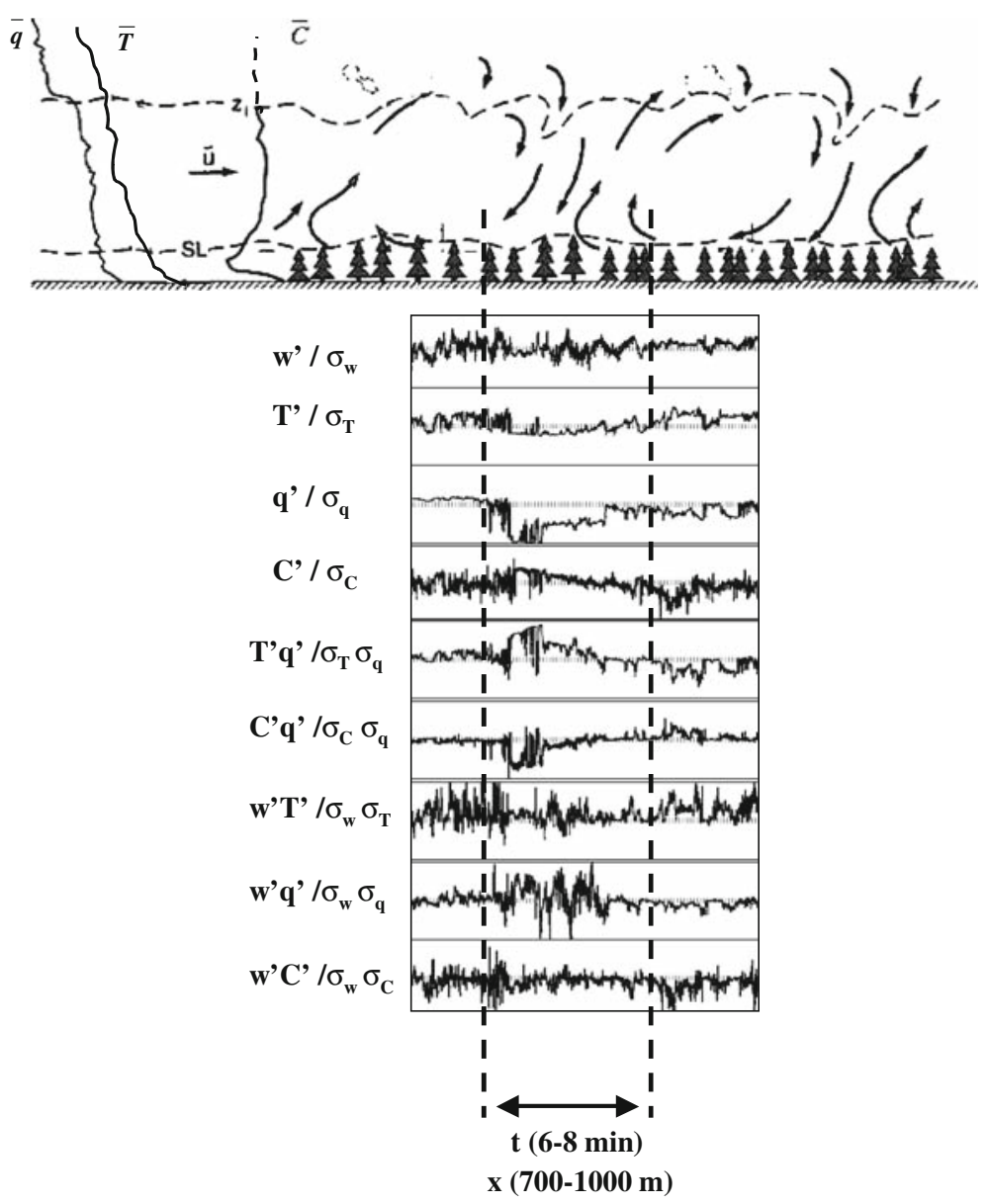

Fig. 13 Top panel: Conceptual diagram of the boundary layer dynamics above a vegetation canopy, showing how the outer-layer modulation might affect the scalar fluctuations in the CSL (revised from Fig. 8 of Roth and Oke 1995). The expected mean scalar concentration profiles here are shown for illustrating the mechanism and are not measured above the site. Bottom panels: time series of normalized scalar concentration, fluxes, and two-scalar correlations during a ramp-like event shown in Fig. 12

\subsubsection{Recovery of ASL-Based Transport Efficiencies}

After filtering respiratory events and outer-layer modulations in both the $q$ and $C$ series, the derived FV similarity functions (grey points in Fig. 1b, c) are not identical to MOST functions, though they follow MOST scaling (including a $C_{2}=9.5 \pm 0.5$ for all three scalars). The main differences from MOST functions are in the $C_{1}$ coefficients, with the derived $C_{1}$ appearing higher when compared to heat $\left(C_{1}=3.4 \pm 0.2\right.$ with $R=0.53$ for $q$ and $C_{1}=2.8 \pm 0.2$ with $R=0.48$ for $C$ ). Note that the $R$ values before the filtering operation were negligible with 0.09 for $q$ and 0.002 for $C$. Again, the Appendix discusses the possible spurious correlations for these filtered series as well.

From Eq. 6, the differences in these similarity coefficients are indicative of differences in transport efficiencies. For the filtered series, the relative transport efficiencies do not approach 

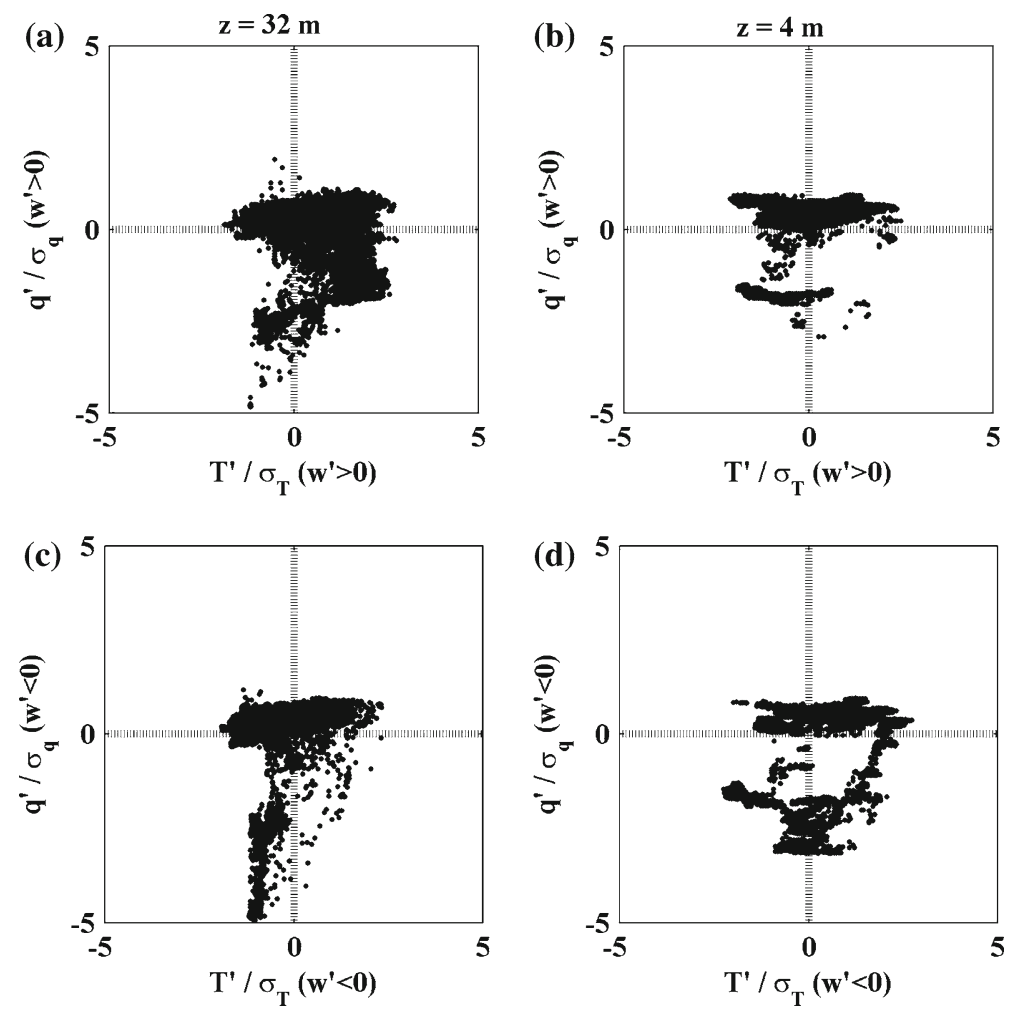

Fig. 14 Quadrant analysis of normalised $q^{\prime}$ versus $T^{\prime}$, conditioned on the basis of occurrence of (a) ejection events or updrafts $\left(w^{\prime}>0\right)$, and of (c) sweeping events or downdrafts $\left(w^{\prime}<0\right)$ for data sampled above the canopy top $(z=32 \mathrm{~m})$. The same analysis for data sampled near the forest floor $(z=4 \mathrm{~m})$ is also shown in (b) and (d), respectively, for reference. Data are relative to the time series shown in Fig. 12

unity as expected for the ASL (see Fig. 2, grey points), but this is not surprising for the CSL. Roughly, heat remains more efficiently transported than water vapour $(\approx 1.8$ times $)$ and $\mathrm{CO}_{2}$ $(\approx 1.2$ times $)$. In fact even in the ASL, heat is usually transported more efficiently because of other factors such as the active role of buoyancy in turbulent kinetic energy production. Furthermore, $\mathrm{CO}_{2}$ appears more efficiently transported than water vapour $(\approx 1.4$ times $)$.

It should be emphasized that these measurements are in the CSL and are influenced by a number of inhomogeneities; hence perfect similarity between heat, water vapour, and $\mathrm{CO}_{2}$ cannot be expected in this layer. What is important to note from the analysis is that the anomalous events identified earlier introduce scatter much larger than factors of 1.2 or 1.5 , as evidenced in Fig. 1.

\section{Discussion and Conclusions}

Historically, disagreements between MOST predictions and measured FV similarity functions proved to be successful in 'fingerprinting' novel dynamics within the ASL. Examples of this success include studies that documented the role of atmospheric boundary-layer height variations on measured $\sigma_{u} / u_{*}$ collected within the ASL (Panofsky and Dutton 1984; 
Hogstrom 1990; De Bruin et al. 1993). Such studies provided early evidence that inactive eddy motion, originating from the outer layer, can affect ASL flow variables such as $\sigma_{u}$. Inactive eddy motion was also shown to modify the root-mean-squared turbulent pressure fluctuations within the ASL (Katul et al. 1996). McNaughton and Brunet (2002) even argued that interactions between such inactive and active eddy motions responsible for momentum transfer are also possible within the ASL and proposed a simplified mechanism for its onset. Likewise, a large number of studies (Wesley 1988; Weaver 1990; Padro 1993; Andreas et al. 1998) have shown how source-sink in-homogeneity at the ground induces departure between measured FV similarity functions and predictions from MOST.

The next logical extension is whether FV similarity analysis can be used to identify the main mechanisms modulating the CSL. While lacking the 'niceties' of MOST formulations as a reference model for an idealized flow state, the FV similarity functions for scalars in the CSL may provide important clues about the role of outer-layer modulations and source-sink dissimilarity in describing CSL turbulence. Mainly, the basic premise is that such complex mechanisms do not affect proportionally the scalar fluxes and their variances.

Our analysis showed that within the CSL of a dense vegetated canopy, both outer-layer processes and heterogeneities in sources and sinks within the canopy volume affect FV similarity functions. Spectral and cospectral analysis suggested that scalar variances were much more sensitive to these two mechanisms than scalar fluxes. For water vapour, the outer-layer contribution to scalar fluxes can be significant when the latent heat flux is small compared to the sensible heat flux in agreement with recent studies (Lamaud and Irvine 2006). Because of the observed positive correlation between $T$ and $q$ (transport of dry and cold air), it can hypothesised that the effect of air directly entrained from the free atmosphere is less significant than the effect of air transported from other zones within the outer layer (as observed in Roth and Oke 1995). Moreover, in the alpine forest studied here, where no major industry or urban centre is present, the contribution of outer-layer modulations to $\mathrm{CO}_{2}$ appears small compared to the intermittent accumulation-ejection cycle of $\mathrm{CO}_{2}$ inside the canopy volume. In fact, respired $\mathrm{CO}_{2}$ from the forest floor was shown to lead to large positive excursions in the $C$ time series at the canopy top thereby contributing significantly to both $\mathrm{CO}_{2}$ variance and vertical flux. The same process may affect the $q$ time series in a similar way in more open canopies and in the presence of a wet forest floor (for example, after a rain event).

The data analysis here showed that if these large-scale outer-layer modulations and ejection-accumulation events are 'filtered out' from the water vapour and $\mathrm{CO}_{2}$ concentration time series, respectively, MOST scaling is approximately recovered.

Finally, other important processes that can produce anomalous scaling in FV similarity functions, such as advection, were not considered. It is difficult to explore these processes via single tower measurements, though some theoretical and experimental attempts are presented in Assouline et al. (2008) for heat and water vapour above small reservoirs. Recent studies (Feigenwinter et al. 2004; Aubinet et al. 2005; Sun et al. 2007) found that advection may be significant even during daytime especially with low intensity turbulence. However, the main concern refers to nocturnal conditions when an underestimation of $\mathrm{CO}_{2}$ fluxes using the eddy-covariance technique frequently occurs because non-turbulent transport processes, not taken into account by the eddy-covariance system, become significant. Under these conditions, quantifying and understanding advective transport processes may be important for the improvement of flux measurements. It is possible that departures from MOST scaling for FV may provide additional clues as to when $\mathrm{CO}_{2}$ advection is important. However, Feigenwinter et al. 2004, Aubinet et al. 2005, Sun et al. 2007 do not discuss the role of advection on FV similarity functions (only on $\mathrm{CO}_{2}$ fluxes via the mean scalar continuity). 
The broader implications of these findings are three-fold. The first pertains to the surface energy balance studies and energy balance closure. If outer-layer modulation can be significant and detected in the water vapour concentration series, then it can also affect eddycovariance water vapour turbulent flux measurements in the CSL. However, net radiation measurements are insensitive to such outer-layer modulations. Whether this mechanism alone may explain the lack of surface energy balance closure is subject to some debate (Steinfeld et al. 2007). For example, the performed analysis showed that during a 6-min sweeping event of dry and cold air from the outer layer, the local latent heat flux actually increased (not decreased). The contributions to sensible heat flux by such events may vary as well. Here, their contribution to sensible heat was not very significant when compared to fluxes originating from within the canopy.

The second pertains to the use of the energy balance closure for latent heat flux to 'correct' or 'adjust' net ecosystem $\mathrm{CO}_{2}$ exchange (NEE) (Twine et al. 2000). Clearly, this approach lacks any theoretical basis given the spectral and cospectral dissimilarities of these two scalars in the CSL. While the measured FV similarity functions for $\mathrm{CO}_{2}$ and water vapour appeared higher than for heat, the mechanisms producing this increase were different. For water vapour, the increase was connected to the entrainment of dry air, while for $\mathrm{CO}_{2}$ it was mainly connected with contributions from an ejection-accumulation cycle of respired $\mathrm{CO}_{2}$. These two mechanisms differ in their contribution to the spectra and cospectra of water vapour and $\mathrm{CO}_{2}$ concentrations.

The third pertains to the inference of respiration events on NEE measurements within the CSL. It is clear that the main reason for the measured FV similarity function for $\mathrm{CO}_{2}$ appearing systematically larger than predictions by MOST is connected with the role of respiration (at this stand). This study demonstrated that when $\mathrm{CO}_{2}$ actually follows MOST scaling, the respiration contribution to NEE above the canopy is small. Hence, it is conceivable that a combination of conditional sampling schemes, quadrant analysis, and FV similarity functions may offer a promising method to extract daytime respiration from NEE time series above the canopy, at least for some limited observations. Given the existence of a large FluxNet database (Baldocchi et al. 2001) already collected over the past decade, the latter implication awaits systematic investigation.

Acknowledgements G. Katul acknowledges support from the US Department of Energy (DOE) through the Office of Biological and Environmental Research (BER) Terrestrial Carbon Processes (TCP) program (Grants \# 10509-0152, DE-FG02-00ER53015, and DE-FG02-95ER62083), from the National Science Foundation (NSF-EAR 06-28342 and 06-35787), and from the Bi-national Agricultural and Research Development (BARD) fund (Grant \#. IS3861-06). D. Cava acknowledges the Italian MIUR Project: 'Sviluppo di un Sistema Integrato Modellistica Numerica-Strumentazione e Tecnologie Avanzate per lo Studio e le Previsioni del Trasporto e della Diffusione di Inquinanti in Atmosfera', grant "Bando 1105/2002 project n. 245" and support from 'Cooperazione Italia-USA su Scienza e Tecnologia dei Cambiamenti Climatici, Anno 2006-2008'.

\section{Appendix: Verification of Spurious Correlations}

An inherent problem in assessing MOST scaling, originally pointed out by Hicks (1978, 1981), is related to 'virtual' or 'spurious' correlations arising because measured $u_{*}$ affects both the dependent and independent states being analysed. De Bruin (1982) and De Bruin et al. (1993) discussed this problem in the context of the FV method and showed that the $-1 / 3$ power-law dependence between $\sigma_{s} / s_{*}$ and $\zeta$ may be merely an artefact of the grouping variables. In fact, $s_{*}$ contains $u_{*}$ and $L$ contains $u_{*}^{3}$. They concluded that the only way to show that spurious correlation effects are not important is to compare the estimated fluxes 
Fig. 15 Dimensionless standard deviation as a function of $-\zeta$ for (a) $T$, (b) $q$ and (c) $C$, produced by randomising the friction velocities. Symbols and lines are the same of Fig. 1
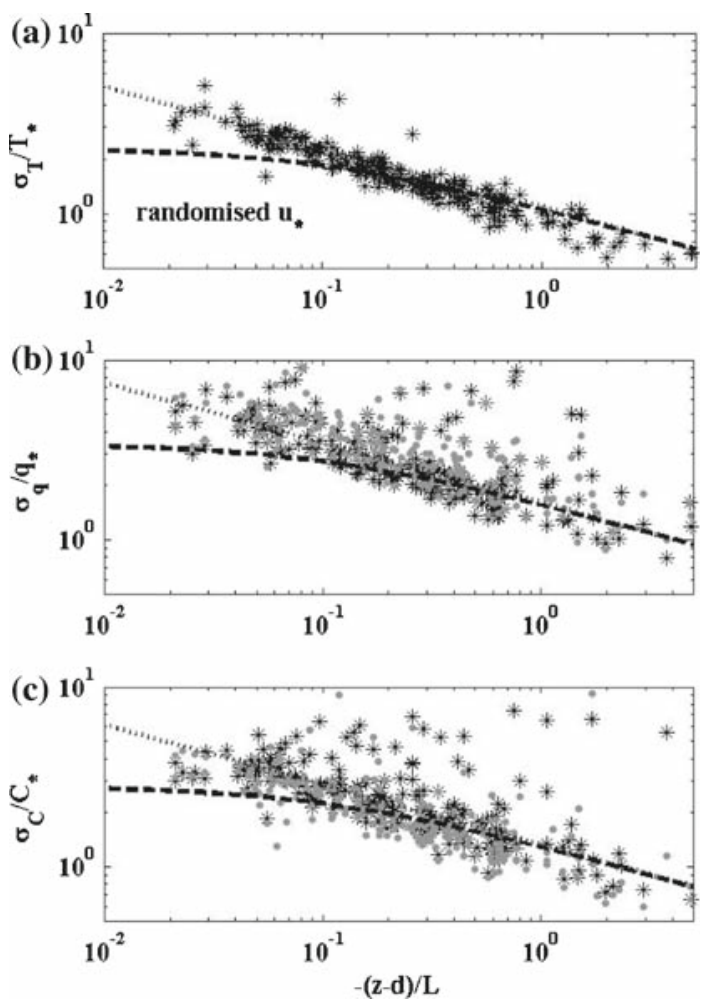

with independent flux measurements. More recent studies by Andreas and Hicks (2002) and Hartogensis and de Bruin (2005) deal with other MOST relationships.

To check whether the FV similarity relationships here reflect the statistics of the common variables rather than the fundamentals of turbulent scaling, the original datasets have been compared with data produced by randomising the friction velocities but retained the same sensible heat, scalar variance and fluxes (Fig. 15). In particular each 30-min measured value of $u_{*}$ was replaced by a $u_{*}$ drawn from a random-normal distribution having a 'global' mean and variance equal to the overall data mean and variance (i.e. when combining all the selected 30-min measured $u_{*}$ ). In this way, $u_{*}$ entering into the calculations of $s_{*}$ and $L$ has no relationship to the true $u_{*}$ measured during those conditions when $\sigma_{S}$ and $\overline{w^{\prime} T^{\prime}}$ were selected. Figure 15 shows that using a randomised $u_{*}$, the modelled FV similarity follows a $-1 / 3$ power law over the entire range of stability conditions. It is noteworthy that towards the nearneutral regime (where mechanical effects are more important than buoyancy), the randomised quantities erroneously follow the $-1 / 3$ power law, but the measured quantities follow the predicted similarity functions. As a consequence, the correlations are not 'spurious' in the near-neutral regimes.

To explore the nature of the correlations obtained in the convection regime, fluxes measured with eddy-correlation technique (correspondent to $\left(-\frac{z-d}{L}\right)>0.2$ ) have been compared to modelled fluxes obtained by using the obtained similarity functions for free convection $\left(\frac{\sigma_{S}}{s_{*}}=C_{3}(-\zeta)^{-1 / 3}\right.$ where $\left.C_{3}=C_{1} C_{2}^{-1 / 3}\right)$ and thus have eliminated entirely the dependence from $u_{*}$ : 
(a)

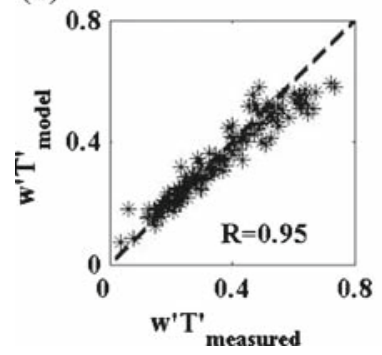

(b) $\times 10^{-3}$

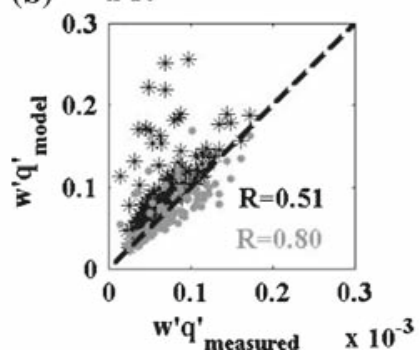

(c)

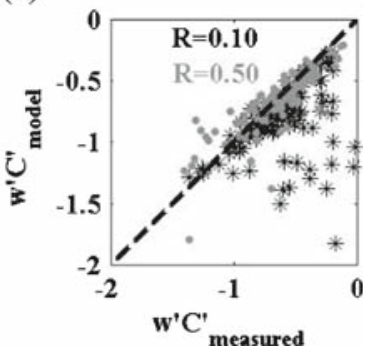

Fig. 16 Turbulent fluxes of (a) $T$, (b) $q$ and (c) $C$, measured directly using eddy-correlation technique versus the correspondent fluxes modelled by using equation (7), which is independent of $u_{*}$. Symbols are the same as in Fig. 1. For reference the 1:1 lines are also shown (dashed lines)

$$
\overline{w^{\prime} s^{\prime}}=\left(\overline{w^{\prime} T^{\prime}}\right)^{1 / 3} \frac{\sigma_{s}}{C_{3}}\left[\frac{(z-d) k g}{\bar{T}}\right]^{1 / 3}
$$

Figure 16 shows good agreement between measured and modelled fluxes, in particular for the data with 'anomalous events' filtered out from the $q$ and $C$ time series (see linear correlation coefficients). On the basis of this result, it can be concluded that the correlations obtained towards the convection regime are not statistical artefacts.

\section{References}

Albertson JD, Parlange MB, Katul GG, Chu CR, Stricker H (1995) Sensible heat flux from arid regions - a simple flux-variance method. Water Resour Res 31(4):969-973

Andreas EL, Hill RJ, Gosz JR, Moore DI, Otto WD, Sarma AD (1998) Statistics of surface-layer turbulence over terrain with metre-scale heterogeneity. Boundary-Layer Meteorol 86(3):379-408

Andreas EL, Hicks BB (2002) Comments on "critical test of the validity of Moni-Obukhov similarity during convective conditions". J Atmos Sci 59:2605-2607

Asanuma J, Tamagawa I, Ishikawa H, Ma YM, Hayashi T, Qi YQ, Wang JM (2007) Spectral similarity between scalars at very low frequencies in the unstable atmospheric surface layer over the Tibetan plateau. Boundary-Layer Meteorol 122(1):85-103

Assouline S, Tyler S, Tanny J, Cohen S, Bou-Zeid E, Parlange MB, Katul GG (2008) Evaporation from three water bodies of different sizes and climates: Measurements and scaling Analysis. Adv Water Resour $31: 160-172$

Aubinet M, Berbigier P, Bernhofer Ch, Cescatti A, Feigenwinter C, Granier A, Grünwald Th, Havrankova K, Heinesch B, Longdoz B, Marcolla B, Montagnani L, Sedlak P (2005) Comparing $\mathrm{CO}_{2}$ storage and advection conditions at night at different CARBOEUROFLUX sites. Boundary-Layer Meteorol 116: 63-94

Baldocchi DD, Falge E, Gu L, Olson R, Hollinger D, Running S, Anthoni P, Bernhofer Ch, Davis K, Fuentes J, Goldstein A, Katul G, Law B, Lee X, Malhi Y, Meyers T, Munger JW, Oechel W, Pilegaard K, Schmid HP, Valentini R, Verma S, Vesala T, Wilson K, Wofsy S (2001) FLUXNET: a new tool to study the temporal and spatial variability of ecosystem-scale carbon dioxide, water vapor and energy flux densities. Bull Amer Meteorol Soc 82:2415-2435

Bink NJ (1996) The structure of the atmospheric surface layer subject to local advection. Ph.D. Thesis, Wageningen Agricultural University, $206 \mathrm{pp}$

Bink NJ, Meesters GCA (1999) Comment on estimation of surface heat and momentum fluxes using the flux-variance method above uniform and non-uniform terrain. In: Katul et al. (1995). Boundary-Layer Meteorol 84:497-502

Brunet Y, Irvine MR (2000) The control of coherent eddies in vegetation canopies: streamwise structure spacing, canopy shear scale and atmospheric stability. Boundary-Layer Meteorol 94(1):139-163

Businger JA (1973) Turbulent transfer in the atmospheric surface layer. In: Haugen DA (ed) Workshop on Micrometeorology. American Meteorological Society, 392 pp 
Cava D, Katul GG, Scrimieri A, Poggi D, Cescatti A, Giostra U (2006) Buoyancy and the sensible heat flux budget within dense canopies. Boundary-Layer Meteorol 118(1):217-240

Choi TKJ, Lee H, Hong J, Asanuma J, Ishikawa H, Gao Z, Wang J, Koike T (2004) Turbulent exchange of heat, water vapor and momentum over a Tibetan praire by eddy covariance and flux-variance measurements. J Geophys Res-Atmos 109(D21):D21106

Cullen NJ, Steffen K, Blanken PD (2007) Nonstationarity of turbulent heat fluxes at Summit, Greenland. Boundary-Layer Meteorol 122(2):439-455

de Arellano JVG, Gioli B, Miglietta F, Jonker HJJ, Baltink HK, Hutjes RWA, Holtslag AAM (2004) Entrainment process of carbon dioxide in the atmospheric boundary layer. J Geophys Res-Atmos 109(D18):D18110

De Bruin HAR (1982) The energy balance at the earth's surface: a practical approach. Ph.D. thesis, Wageningen Agricultural University. (also K.N.M.I., Sci. Rep. 81-1)

De Bruin HAR, Kohsiek W, Van Den Hurk BJJM (1993) A verification of some methods to determine the fluxes of momentum, sensible heat, and water-vapor using standard-deviation and structure parameter of scalar meteorological quantities. Boundary-Layer Meteorol 63(3):231-257

De Bruin HAR (1994) Analytic solutions of the equations governing the temperature fluctuation method. Boundary-Layer Meteorol 68:427-432

De Bruin HAR, Van Den Hurk BJJM, Kroon LJM (1999) On the temperature-humidity correlation and similarity. Boundary-Layer Meteorol 93:453-468

Detto M, Katul GG (2007) Simplified expressions for adjusting higher-order turbulent statistics obtained from open path gas analyzers. Boundary-Layer Meteorol 122(1):205-216

Detto M, Katul GG, Mancini M, Montaldo N, Albertson J (2008) Surface heterogeneity and its signature in higher-order scalar similarity relationships. Agric For Meteorol (In press)

Finnigan J (2000) Turbulence in plant canopies. Ann Rev Fluid Mech 32:519-571

Feigenwinter C, Bernhofer C, Vogt R (2004) The influence of advection on the short term $\mathrm{CO}_{2}$-budget in and above a forest canopy. Boundary-Layer Meteorol 113:201-224

Garratt JR (1978) Flux profile relations above tall vegetation. Quart J Roy Meteorol Soc 104:199-211

Garratt JR (1980) Surface influence upon vertical profiles in the atmospheric near-surface layer. Quart J Roy Meteorol Soc 106:803-819

Garratt JR (1983) Surface influence upon vertical profiles in the nocturnal boundary layer. Boundary-Layer Meteorol 26:69-80

Górska M, de Arellano JV, LeMone MA (2006) The exchange of carbon dioxide between the atmospheric boundary layer and the free atmosphere: observational and LES study. In: Extended abstract presented on the 17th AMS Symposium on Boundary Layer and Turbulence, San Diego, paper 1.6

Hartogensis OK, De Bruin HAR (2005) Monin-Obukhov similaruty functions of the structure parameter of temperature and turbulent kinetic energy dissipation rate in the stable boundary layer. Boundary-Layer Meteorol 116:253-276

Hicks BB (1978) Some limitations of dimensional analysis and power laws. Boundary-Layer Meteorol 14:567-569

Hicks BB (1981) An examination of turbulence statistics in the surface boundary layer. Boundary-Layer Meteorol 21:389-402

Hogstrom U, Bergstrom H, Smedman AS, Halldin S, Lindroth A (1989) Turbulent exchange above a Pine forest. 1, fluxes and gradients. Boundary-Layer Meteorol 49(1-2):197-217

Hogstrom U (1990) Analysis of turbulence structure in the surface-layer with a modified similarity formulation for near neutral conditions. J Atmos Sci 47(16):1949-1972

Hogstrom U, Hunt JCR, Smedman AS (2002) Theory and measurements for turbulence spectra and variances in the atmospheric neutral surface layer. Boundary-Layer Meteorol 103(1):101-124

Juang JY, Katul GG, Siqueira MBS, Stoy PC, Palmroth S, McCarthy HR, Kim HS, Oren R (2006) Modeling nighttime ecosystem respiration from measured $\mathrm{CO}_{2}$ concentration and air temperature profiles using inverse methods. J Geophys Res-Atmos 111(D8):D08s05

Kaimal JC, Finnigan JJ (1994) Atmospheric boundary layer flows. Oxford University Press, New York 289 pp

Katul G, Goltz SM, Hsieh CI, Cheng Y, Mowry F, Sigmon J (1995) Estimation of surface heat and momentum fluxes using the flux-variance method above uniform and nonuniform terrain. Boundary-Layer Meteorol 74(3):237-260

Katul GG, Albertson JD, Hsieh CI, Conklin PS, Sigmon JT, Parlange MB, Knoerr KR (1996) The "inactive" eddy motion and the large-scale turbulent pressure fluctuations in the dynamic sublayer. J Atmos Sci 53(17):2512-2524

Katul GG, Hsieh CI (1999) A note on the flux-variance similarity relationships for heat and water vapour in the unstable atmospheric surface layer. Boundary-Layer Meteorol 90(2):327-338 
Katul GG, Sempreviva AM, Cava D (2008) The temperature-humidity covariance in the marine surface layer: a one-dimensional analytical model. Boundary-Layer Meteorol 126(2):263-278

Kohsiek W, De Bruin HAR, The H, Van Den Hurk B (1993) Estimation of the sensible heat flux of a semi-arid area using surface radiative temperature measurements. Boundary-Layer Meteorol 63(3):231-230

Kroon LJM, De Bruin HAR (1995) The Crau field experiment—turbulent exchange in the surface-layer under conditions of strong local advection. J Hydrol 166(3-4):327-351

Kustas WP, Blanford JH, Stannard DI, Daughtry CST, Nichols WD, Weltz MA (1994) Local energy flux estimates for unstable conditions using variance data in semiarid rangelands. Water Resour Res 30(5): 1351-1361

Lamaud E, Irvine M (2006) Temperature-humidity dissimilarity and heat-to-water-vapour transport efficiency above and within a pine forest canopy: the role of the Bowen ratio. Boundary-Layer Meteorol 120(1): 87-109

Leclerc MY, Beissner KC, Shaw RH, Den Hartog G, Neumann HH (1990) The influence of atmospheric stability on the budgets of the reynolds stress and turbulent kinetic energy within and above a deciduous forest. J Appl Meteorol 29:916-933

Lyons TJ, Fuqin L, Hacker JM, Cheng WL, Huang XM (2001) Regional turbulent statistics over contrasting natural surfaces. Meteorol Atmos Phys 78(3-4):183-194

Mahrt L (1991a) Boundary-layer moisture regimes. Quart J Roy Meteorol Soc 117(497):151-176

Mahrt L (1991b) Eddy asymmetry in the sheared heated boundary-layer. J Atmos Sci 48(3):472-492

Marcolla B, Pitacco A, Cescatti A (2003) Canopy architecture and turbulence structure in a coniferous forest. Boundary-Layer Meteorol 108(1):39-59

McNaughton KG, Brunet Y (2002) Townsend's hypothesis, coherent structures and Monin-Obukhov similarity. Boundary-Layer Meteorol 102(2):161-175

McNaughton KG, Laubach J (1998) Unsteadiness as a cause of non-equality of eddy diffusivities for heat and vapour at the base of an advective inversion. Boundary-Layer Meteorol 88(3):479-504

McNaughton KG, Laubach J (2000) Power spectra and cospectra for wind and scalars in a disturbed surface layer at the base of an advective inversion. Boundary-Layer Meteorol 96(1-2):143-185

Mölder M, Grelle A, Lindroth A, Halldin S (1999) Flux-profile relationships over a boreal forest—roughness sublayer corrections. Agric For Meteorol 98(9):645-658

Moene AF, Schüttemeyer D, Hartogensis OK (2006) Scalar similarity functions: the influence of surface heterogeneity and entrainment. In Extended abstract presented on the 17th AMS Symposium on Boundary Layer and Turbulence, San Diego, paper 5.1

Moriwaki R, Kanda M (2006) Local and global similarity in turbulent transfer of heat, water vapour, and $\mathrm{CO}_{2}$ in the dynamic convective sublayer over a suburban area. Boundary-Layer Meteorol 120(1):163-179

Ohtaki E (1985) On the similarity in atmospheric fluctuations of carbon-dioxide, water-vapor and temperature over vegetated fields. Boundary-Layer Meteorol 32(1):25-37

Padro J (1993) An investigation of flux-variance methods and universal functions applied to 3 land-use types in unstable conditions. Boundary-Layer Meteorol 66(4):413-425

Panofsky HA, Dutton JA (1984) Atmospheric turbulence: models and methods for engineering applications. Wiley, New York, 397 pp

Poggi D, Porporato A, Ridolfi L, Albertson JD, Katul GG (2004) The effect of vegetation density on canopy sub-layer turbulence. Boundary-Layer Meteorol 111(3):565-587

Raupach MR (1979) Anomalies in flux-gradient relationships over forest. Boundary-Layer Meteorol 16:467

Raupach MR, Stewart JB, Thom AS (1979) Analysis of flux-profile relationships above tall vegetation alternative view—comments. Quart J Roy Meteorol Soc 105(446):1077-1078

Raupach MR, Finnigan JJ, Brunet Y (1996) Coherent eddies and turbulence in vegetation canopies: the mixing-layer analogy. Boundary-Layer Meteorol 78(3-4):351-382

Roth M, Oke TR (1995) Relative efficiencies of turbulent transfer of heat, mass, and momentum over a patchy urban surface. J Atmos Sci 52(11):1863-1874

Sempreviva AM, Gryning SE (2000) Mixing height over water and its role on the correlation between temperature and humidity fluctuations in the unstable surface layer. Boundary-Layer Meteorol 97:273-291

Steinfeld G, Letzel MO, Raasch S, Kanda M, Inagaki A (2007) Spatial representativeness of single tower measurements and the imbalance problem with eddy-covariance fluxes: results of a large-eddy simulation study. Boundary-Layer Meteorol 123(1):77-98

Sun J, Burns SP, Delany AC, Oncley SP, Turnipseed AA, Stephens BB, Lenschow DH, LeMone MA, Monson RK, Anderson DE (2007) $\mathrm{CO}_{2}$ transport over complex terrain. Agric Forest Meteorol 145:1-21

Thom AS, Stewart JB, Oliver HR, Gash JHC (1975) Comparison of aerodynamic and energy budget estimates of fluxes over a pine forest. Quart J Roy Meteorol Soc 101:93-105 
Tillman JE (1972) The indirect determination of stability, heat and momentum fluxes in the atmospheric boundary layer from simple scalar variables during dry unstable conditions. J Appl Meteorol 11: $783-792$

Thomas C, Martin JG, Goeckede M, Siqueira MB, Foken T, Law BE, Loescher HW, Katul G (2008) Estimating daytime ecosystem respiration from conditional sampling methods applied to multi-scalar high frequency turbulence time series. Agic For Meteorol (In press)

Twine TE, Kustas WP, Norman JM, Cook DR, Houser PR, Meyers TP, Prueger JH, Starks PJ, Wesely ML (2000) Correcting eddy-covariance flux underestimates over a grassland. Agric For Meteorol 103(3):279-300

Valentini R, Matteucci G, Dolman AJ, Schulze ED, Rebmann C, Moors EJ, Granier A, Gross P, Jensen NO, Pilegaard K, Lindroth A, Grelle A, Bernhofer C, Grunwald T, Aubinet M, Ceulemans R, Kowalski AS, Vesala T, Rannik U, Berbigier P, Loustau D, Guomundsson J, Thorgeirsson H, Ibrom A, Morgenstern K, Clement R, Moncrieff J, Montagnani L, Minerbi S, Jarvis PG (2000) Respiration as the main determinant of carbon balance in European forests. Nature 404(6780):861-865

Weaver HJ (1990) Temperature and humidity flux-variances relations determined by one-dimensional eddycorrelation. Boundary-Layer Meteorol 53:77-91

Webb EK, Pearman GI, Leuning R (1980) Correction of flux measurements for density effects due to heat and water-vapor transfer. Quart J Roy Meteorol Soc 106(447):85-100

Wesley ML (1988) Use of variance techniques to measure dry air-surface exchange rates. Boundary-Layer Meteorol 44:13-31

Wesson KH, Katul G, Lai CT (2001) Sensible heat flux estimation by flux variance and half-order time derivative methods. Water Resource Res 37(9):2333-2343

Williams CA, Scanlon TM, Albertson JD (2007) Influence of surface heterogeneity on scalar dissimilarity in the roughness sublayer. Boundary-Layer Meteorol 122(1):149-165

Wyngaard JC, Cote OR, Izumi Y (1971) Local free convection, similarity, and budgets of shear stress and heat flux. J Atmos Sci 37:271-284 